\title{
PRACTICES OF FEMALE UNIVERSITY STUDENTS TOWARDS THE USE OF TIME RESOURCE And AWARENESS OF IT AND ITS RELATIONSHIP TO THE ASPECTS OF COMPATIBILITY WITH THEM
}

Rehan, E. R.; Heba D. A. Elassal and E. E. Ahmed

Faculty of Specific Education ., Mansoura University

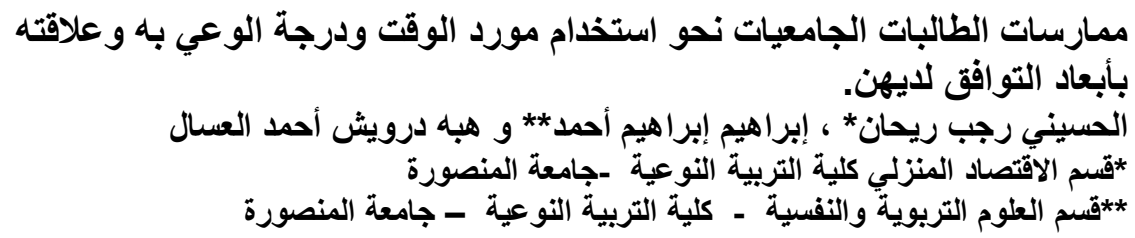

الملخص

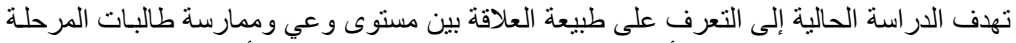

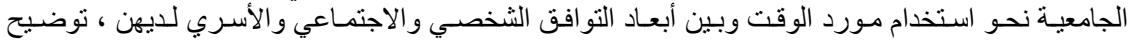

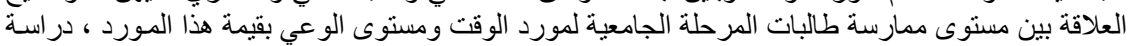

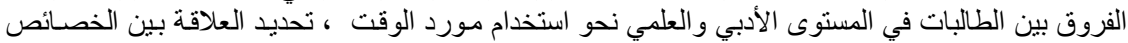

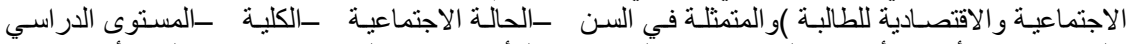

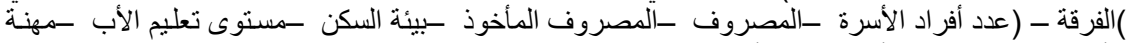

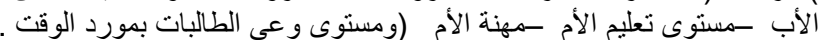

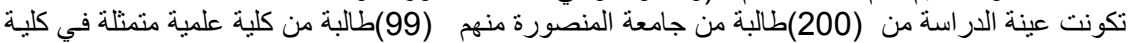

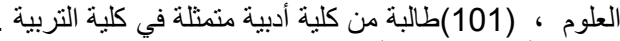

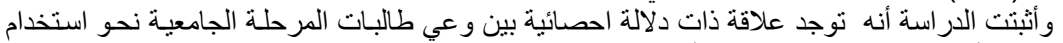

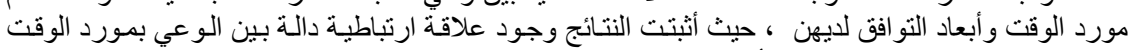

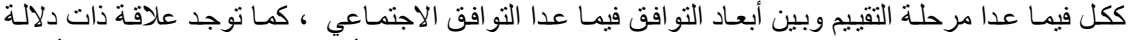

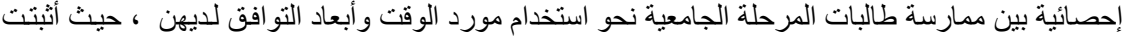

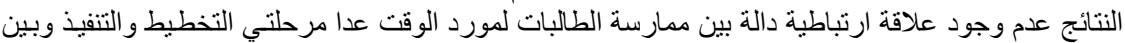

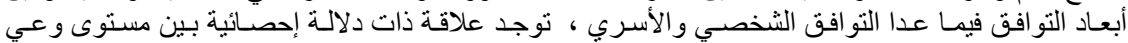

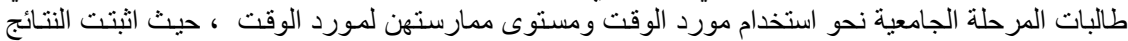

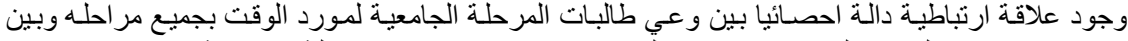

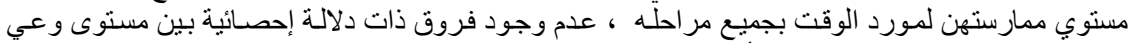

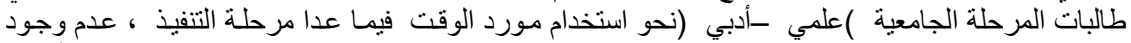

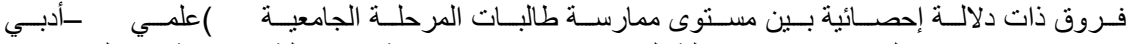

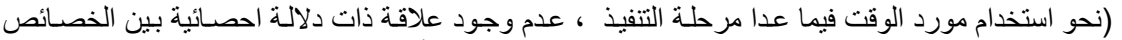

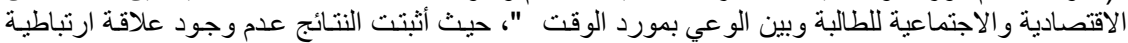

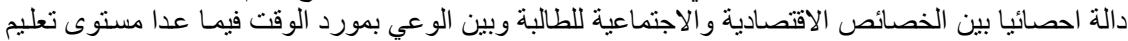

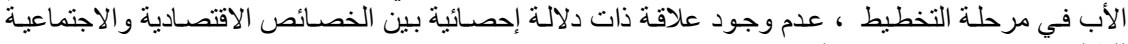

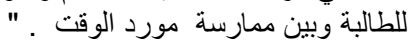

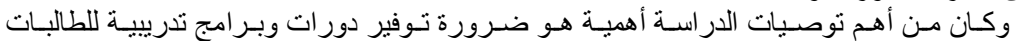

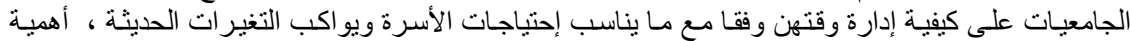
إدخال بعض مناهج إدارة المنزل كإدارة مورد الوقت ، في مختلف التخصصات . 
Rehan, E. R. et al.

\section{المقدمة و المشكلة البحثية}

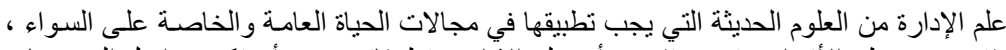

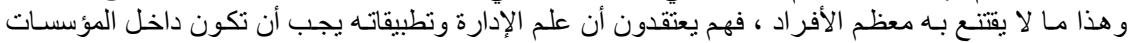

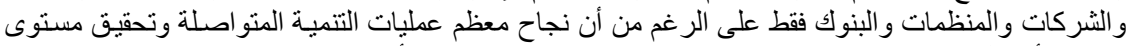

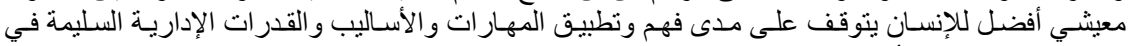

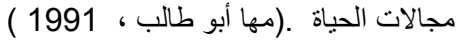

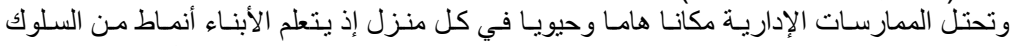

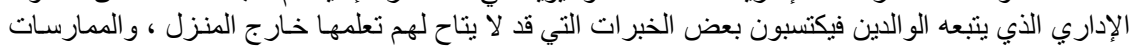

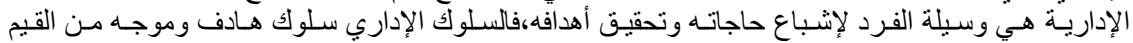

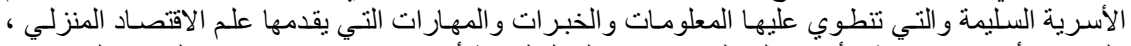

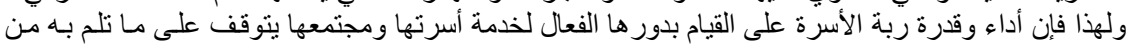

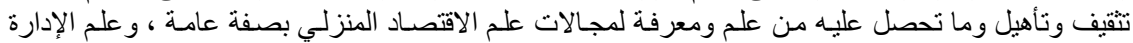

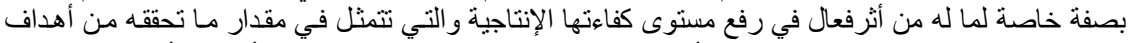

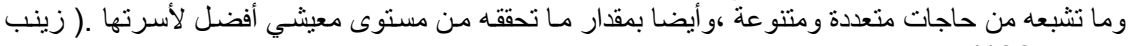

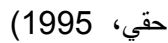

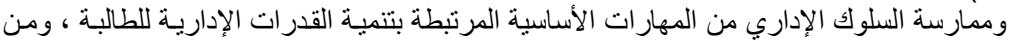

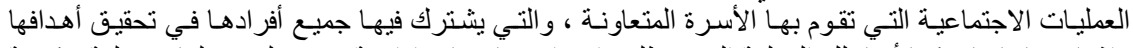

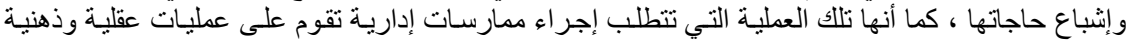

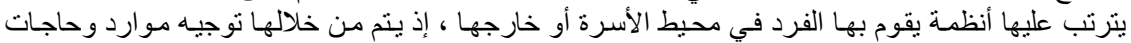

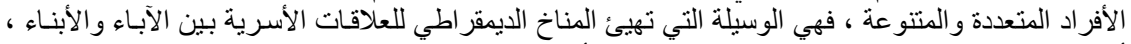

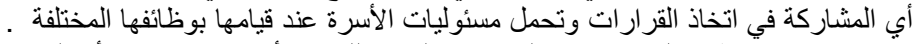

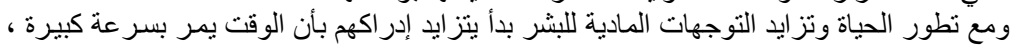

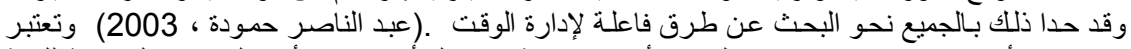

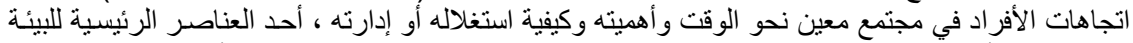

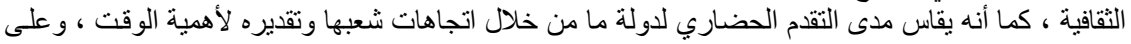

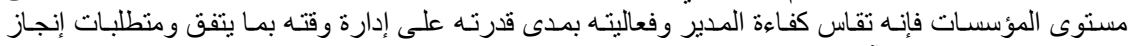

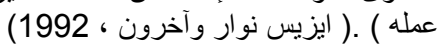

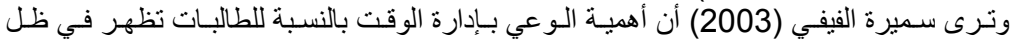

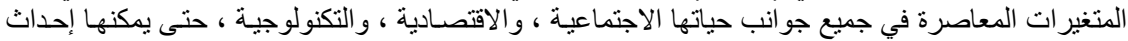

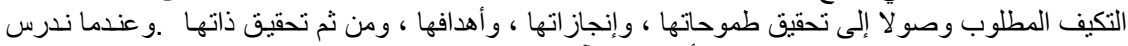

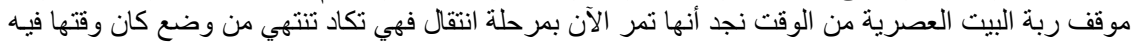

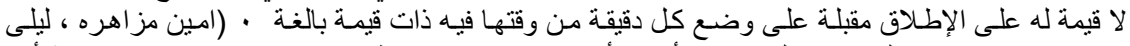

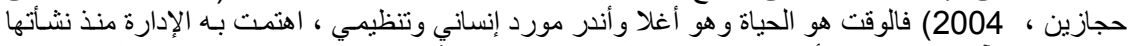

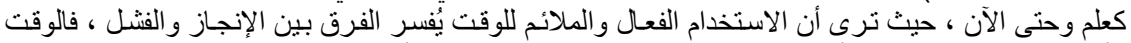

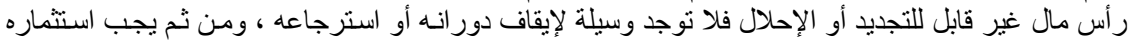

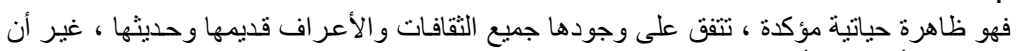
لا إنفاقه

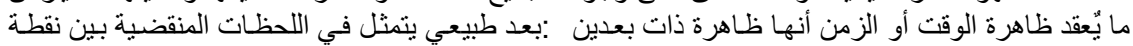

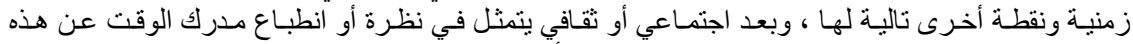

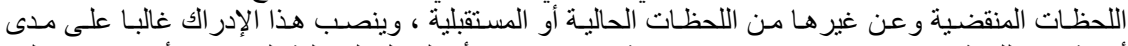

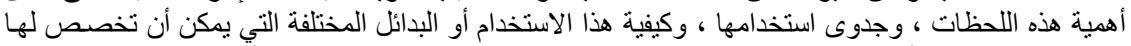

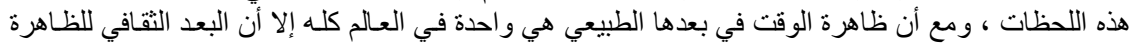

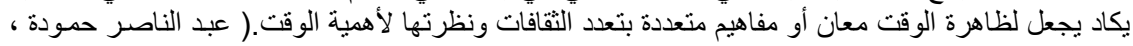

وقد أثبتت الدراسات أن نجاح الفرد الذي يبحث عن أفضل مستوى للمعيثة في مجتمعسه إنما يتوقف (2003

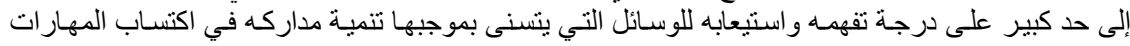




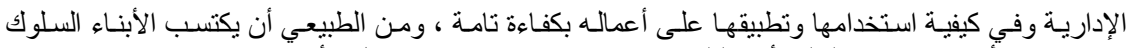

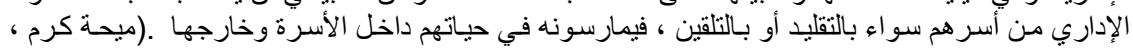

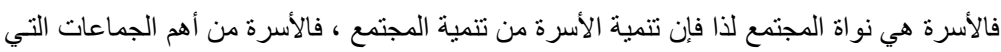

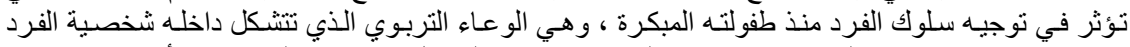

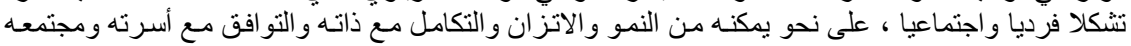

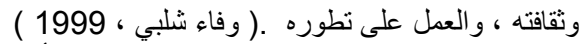

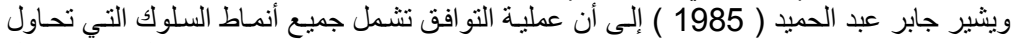

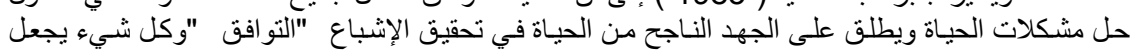

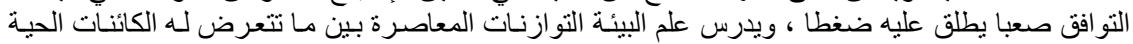

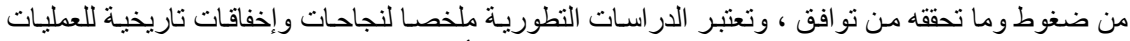

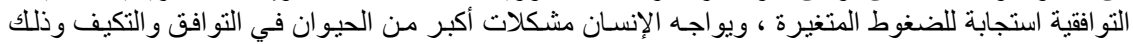

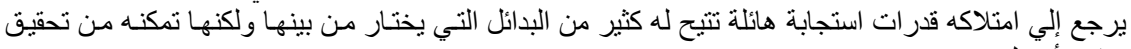

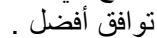

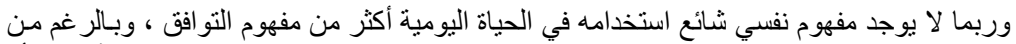

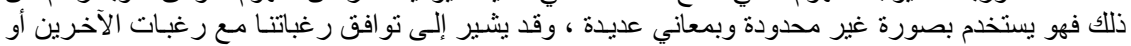

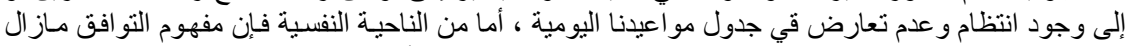

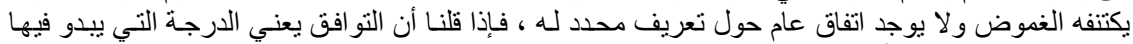

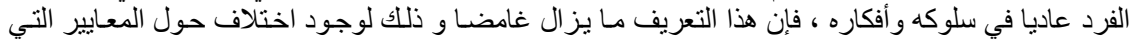

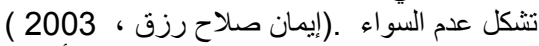

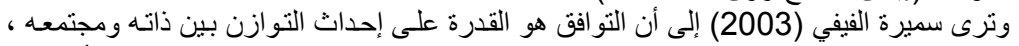

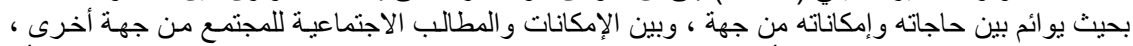

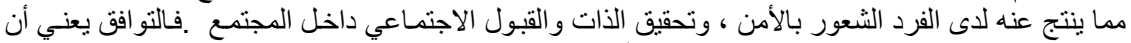

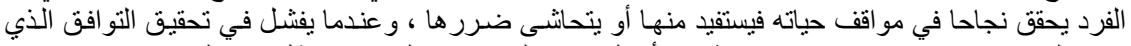

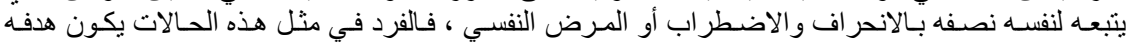

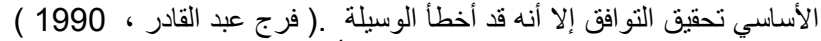

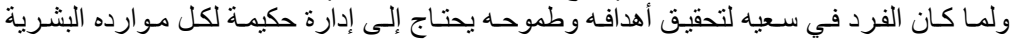

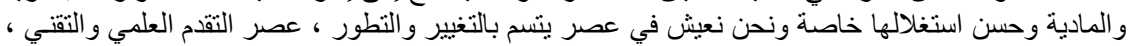

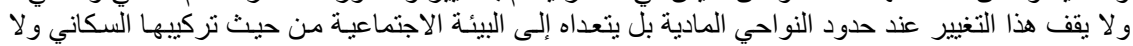

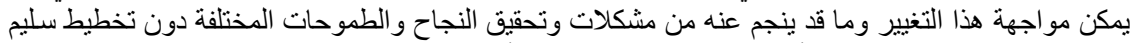

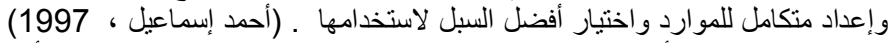

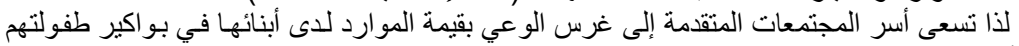

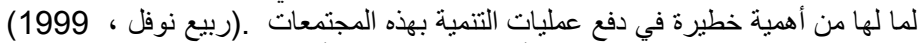

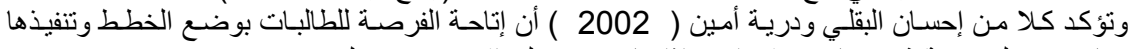

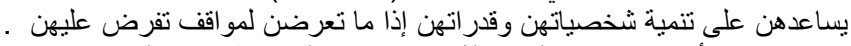

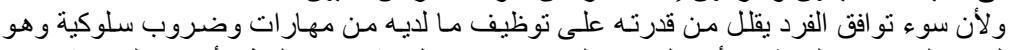

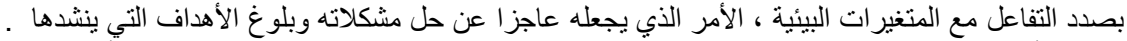

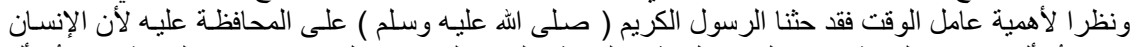

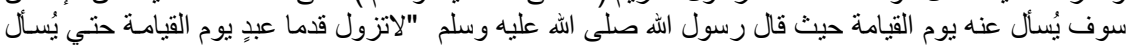

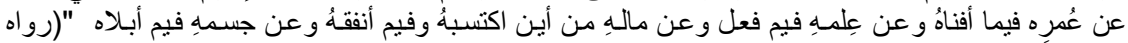

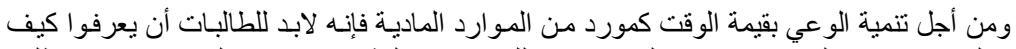
الترمذي).

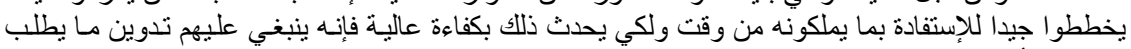

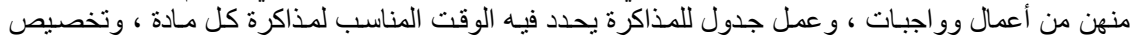

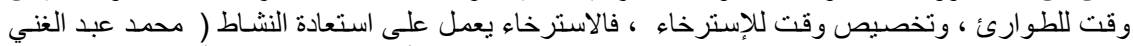
حسن ، 1995 ) ، كذلك فإن استغلال الطالبات لوقت الفراغ ألغ في عمل أشياء مفيدة لهن ولأسر هم كل هذا من 
Rehan, E. R. et al.

ثأنه أن ينمي في الطالبات قيمة الانتماء و الو لاء فتصبح انسانة ملتزمة تعي مسئوليتها أمسام ذاتها وأمسام أسرتها

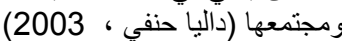

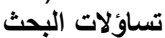

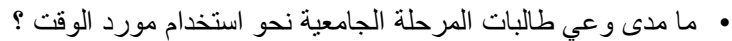

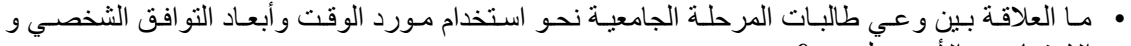

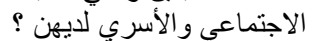

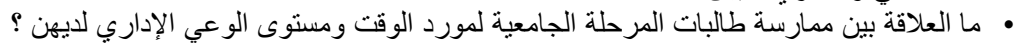

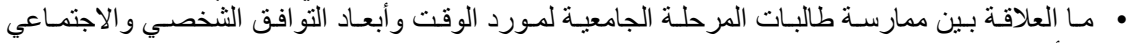

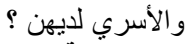

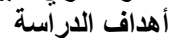

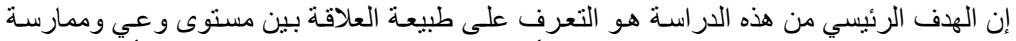

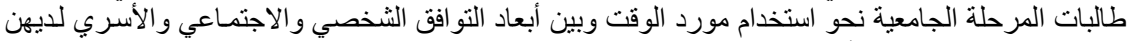
، وذلك من خلال دراسة الأهداف الفر عية التالية :

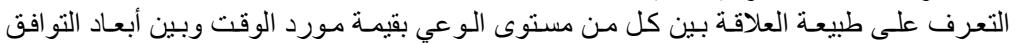

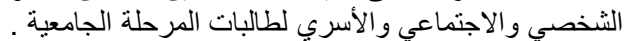

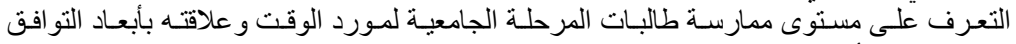

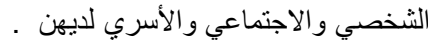

توضيح العلاقة بين مستوى ممارسة طالبات المرحلة الجامعية لمورد الوقت ومستوى الوعي بقيمة

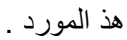
لمراسة الفروق بين الطالبات في المستوى الأدبي والعلمي نحو استخدام مورد الوقت .

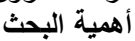

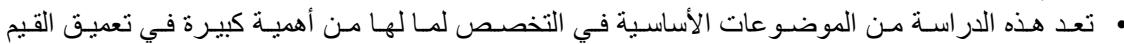

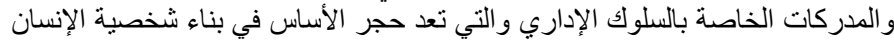

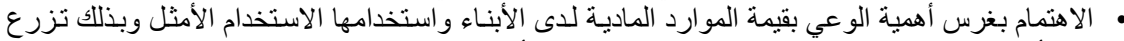

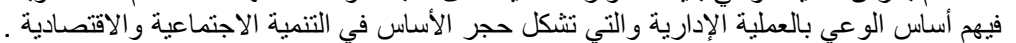

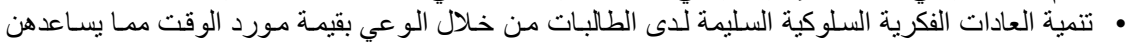

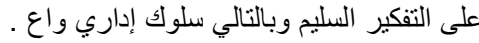

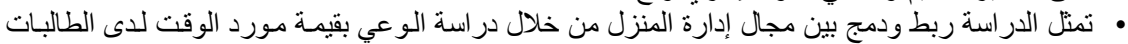

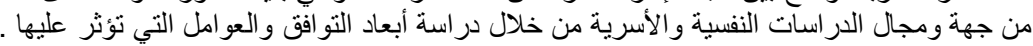

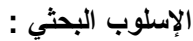

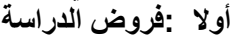
توجد علاقة ذات دلالة إحصائية بين وعي طالبات المرحلة الجامعية نحو استخدام مورد الوقت وأبعاد

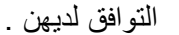

توجد علاقة ذات دلالة إحصائية بين ممارسة طالبـات المرحلة الجامعية نحو استخدام مورد الوقت

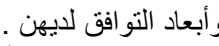
• توجد علاقة ذات دلالكة إحصائية بين مستوى وعي طالبات المرحلة الجامعية نحو استخدام مورد الوقت

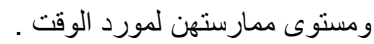

• توجد فروق ذات دلالة إحصائية بين مستوى وعي طالبات المرحلة الجامعية علمي ـأدبي (نحو

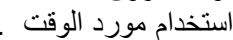

• توجد فروق ذات دلالة إحصائية بين مستوى ممارسة طالبات المرحلة الجامعية علمي ـأدبي (نحو

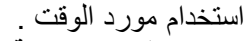
ثنانيا :المصطلحات البحثية

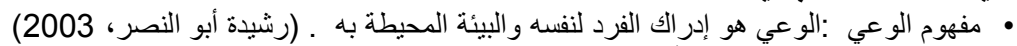

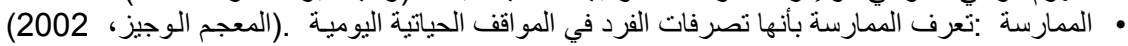

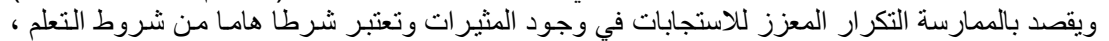
و التعلم هو تغيير شبه دائم في أداء الكائن الحي تؤدي الممارسة فيه دورا رئيسيا ولذللك لا يتحقق التعلم دون 
ممارسة الاستجابات التي تحقق اكتسـاب المهارة المطلوبـة سواء كانت حركية أو لفظية أو عقلية .أنور

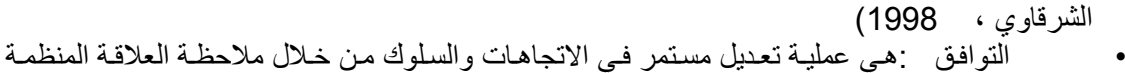

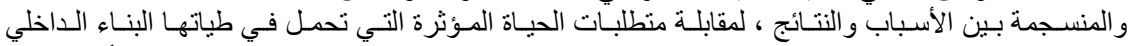

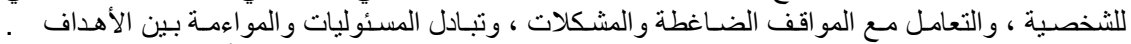

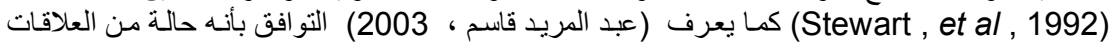

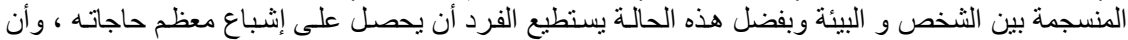

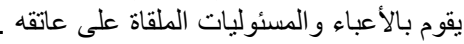

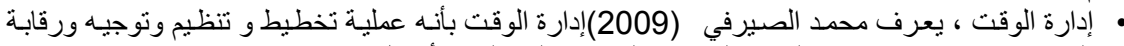

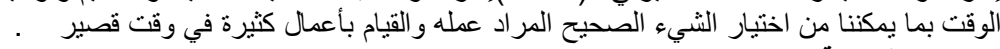

تنتبع هذه الدر اسة المنهج الوصفي التحليلي نظر الملاءمنه لموضوع الدراسة .

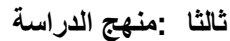

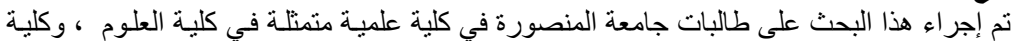

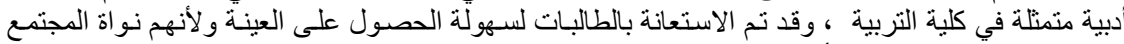

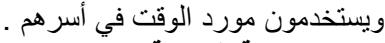
خامسا : عينة الاراسة

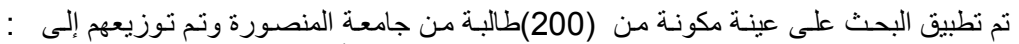

(99)طالبة من كلية علمية منمثلة في كلية العلوم ، (101)طالبة من كلية أدبية منمنلة في كلية التربية . أدوات الدراسة

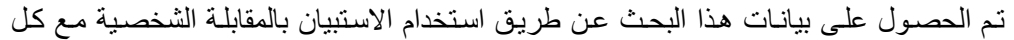

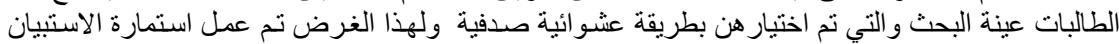

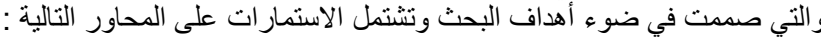

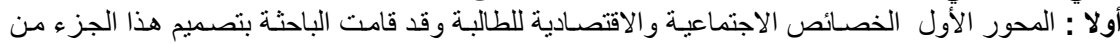

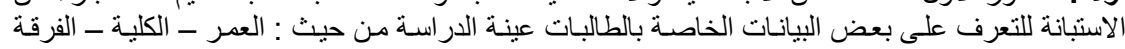

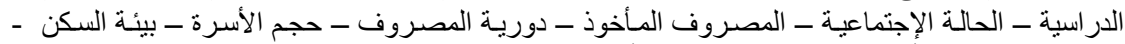

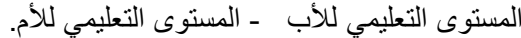

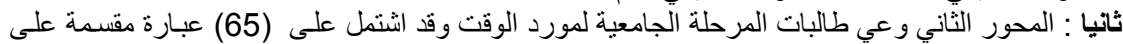

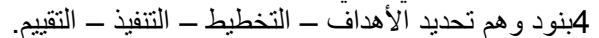

ثُالثا : المحور الثالث ممارسات طالبات المرحلة الجامعية لمورد الوقت وقد اشتمل على ( 36 ) عبارة مقسمة

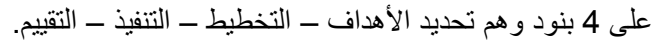
رابعا : المحور الر ابع أبعاد التو افق لدى طالبات الأل المرحلة الجامعية وقد اشتمل على (36) عبارة مقسمة على 3

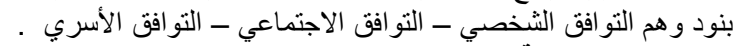
المعاملات الإحصائية

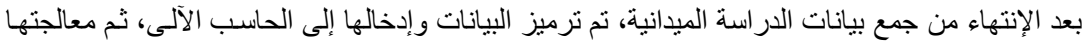

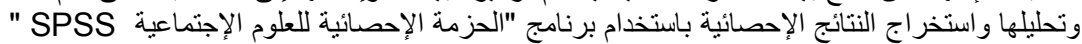

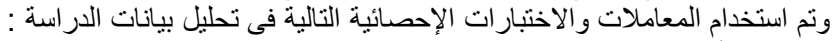

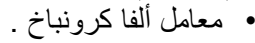

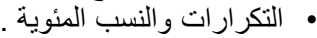
• معامل ارتباط بيرسون . • • • المتوسطات الحسابية والانحر افات المعيارية .

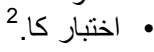

• نتائج الدراسة الميدانية أولا :وصف عينة الدراسة الدية التية • التوزيع النسبي للطالبات الجامعيات عينة الدراسة 
Rehan, E. R. et al.

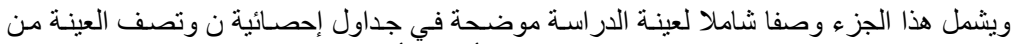

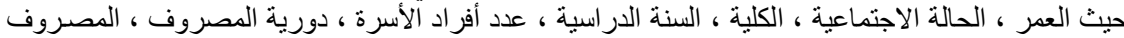
المأخوذ ، بيئة السكن ، مستوى تعليم الأب ، مستوى العنة تعليم الأم .

جدول (1) التوزيع النسبي للطالبات الجامعيات عينة الدراسة تبعا للعمر

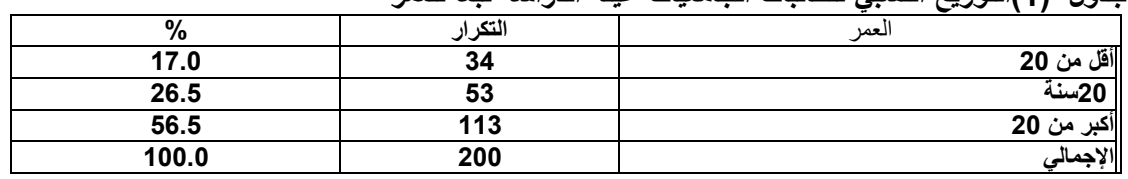

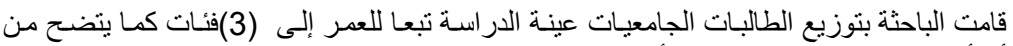

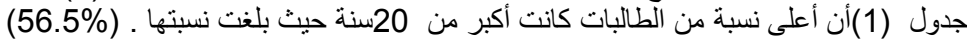

جدول (2) التوزيع النسبي للطالبات الجامعيات عينة الدراسة تبعا للحالة الاجتماعية

\begin{tabular}{|c|c|c|}
\hline$\%$ & التكرار & الحالة الاجتماعية \\
\hline 96.5 & 193 & مالم \\
\hline 3.5 & 7 & روجة \\
\hline 100.0 & 200 & الإجمالي \\
\hline
\end{tabular}

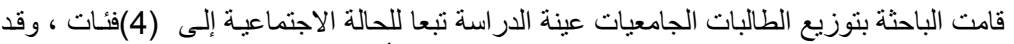

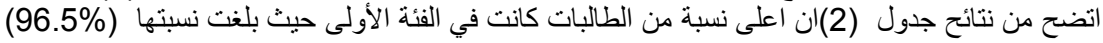
جدول (3) التوزيع النسبي للطالبات الجامعيات عينة الدراسة تبعا للقسم

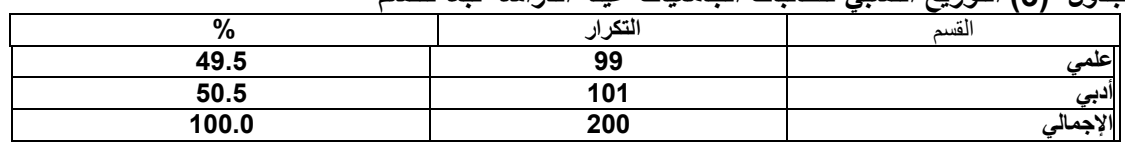

قامت الباحثة بنوزيع الطالبات الجامعيات عينة الدر اسة تبعا للكلية إلى فئتين ، وقد اتضـح من نتائح

جدول (3)ان اعلى نسبة من الطالبات كانت في الفئة الثانية حيث بلثة بلغت نسبتها (50.5\%)

جدول (4) التوزيع النسبي للطالبات الجامعيات عينة الدراسة تبعا للفرقة الدراسية

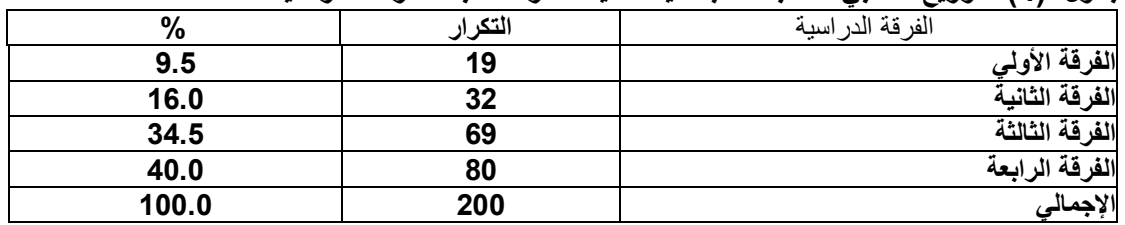

قامت الباحثة بتوزيع الطالبات الجامعيات عينة الدر اسة تبعا للمستوى الدراسي إلى (4)فئسات ، وقد

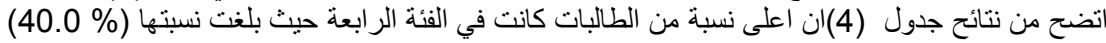

جذول (5) التوزيع النسبي للطالبات الجامعيات عينة الدراسة تبعا لعدد أفراد الأسرة

\begin{tabular}{|c|c|c|}
\hline$\%$ & التكرار & عدد افراد الاسره \\
\hline 8.0 & 16 & أقل من 3أفراد \\
\hline 10.5 & 21 & | \\
\hline 81.5 & 163 & |أكبر من 3أفراد \\
\hline 100.0 & 200 & | الإجمالي \\
\hline
\end{tabular}


قامت الباحثة بتوزيع الطالبات الجامعيات عينة الدر اسة تبعا لعدد أفراد الأسرة إلى (3)فئسات ، وقد (51.5\%

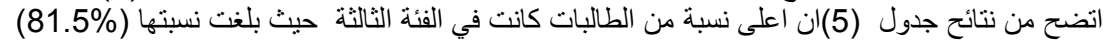

\begin{tabular}{|c|c|c|}
\hline$\%$ & التكرار & قيمة المصروف \\
\hline 46.0 & 92 & أققل من 100 \\
\hline 17.0 & 34 & 100 \\
\hline 37.0 & 74 & أكبر من من 100 \\
\hline 100.0 & 200 & |الإجمالي \\
\hline
\end{tabular}

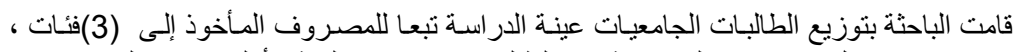

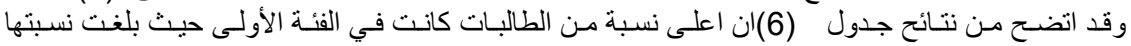

\begin{tabular}{|c|c|c|}
\hline$\%$ & التكرار & دورية المصروف \\
\hline 42.0 & 84 & |يومي \\
\hline 14.5 & 29 & أسبوعي \\
\hline 43.5 & 87 & شهري \\
\hline 100.0 & 200 & الإجمالي \\
\hline
\end{tabular}

قامت الباحثة بتوزيع الطالبات الجامعيات عينة الدر اسة تبعا لدورية المصروف إلى (3)فئات ، وقد

اتضح من نتائح جدول (7)ان اعلى نسبة من الطالبات كانت في الفئة الثالثة حيث بلغت الثنة نسبتها ـ (33.5\%)

جدول (8) التوزيع النسبي للطالبات الجامعيات عينة الدراسة تبعا لبيئة السكن

\begin{tabular}{|c|c|cr|}
\hline$\%$ & ريف \\
\hline 46.5 & 93 & & \\
\hline 53.5 & 107 & & \\
\hline 100.0 & 200 & & \\
\hline
\end{tabular}

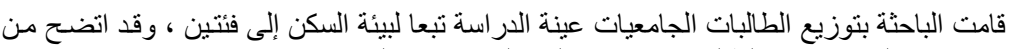

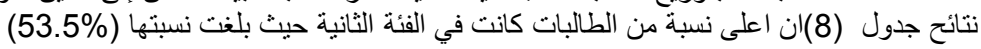

\begin{tabular}{|c|c|c|}
\hline$\%$ & التكرار & مستوى تعليم الاب \\
\hline 11.5 & 23 & |أمى \\
\hline 3.0 & 6 & ابتأئي \\
\hline 28.5 & 57 & متوسط أو دبلوم \\
\hline 2.5 & 5 & ثانوى \\
\hline 49.5 & 99 & جامعى \\
\hline 5.0 & 10 & فوق جامعي \\
\hline 100.0 & 200 & الإجمالي \\
\hline
\end{tabular}

قامت الباحثة بتوزيع الطالبـات الجامعيات عينة الدر اسـة تبعا لمستوى تعليم الأب إلى (6)فئات ،

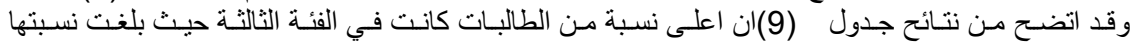

$(49.5 \%)$

جدول (10) التوزيع النسبي للطالبات الجامعيات عينة الدراسة تبعا لمستوى تعليم الأم 1029 
Rehan, E. R. et al.

\begin{tabular}{|c|c|c|}
\hline$\%$ & التكرار & مستوى تعليم الام \\
\hline 17.0 & 34 & |أمي \\
\hline 4.0 & 8 & |بتدائي \\
\hline 33.5 & 67 & متوسطُ أو دبلوم \\
\hline 3.5 & 7 & ثانوى \\
\hline 39.5 & 79 & جامعي \\
\hline 2.5 & 5 & فوق جامعي \\
\hline 100.0 & 200 & |الإجمالي \\
\hline
\end{tabular}

قامت الباحثة بتوزيع الطالبات الجامعيات عينة الدر اسة تبعا لمستوى تعليم الأم إلى (6) فئسات ، وقد

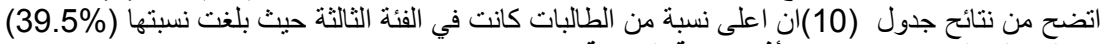

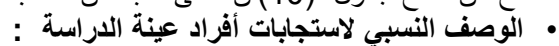

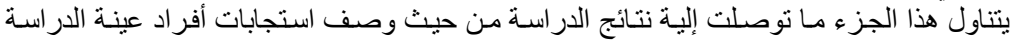

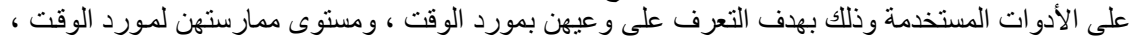

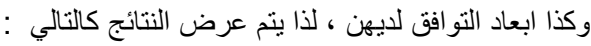

جدول (11) توزيع الطالبات الجامعيات تبعا لمستوى وعيهن بمورد الوقت

\begin{tabular}{|c|c|c|c|c|c|c|c|c|c|c|}
\hline \multicolumn{2}{|c|}{ الدرجة الكلية } & \multicolumn{2}{|c|}{ مرحلة التقييم } & \multicolumn{2}{|c|}{ مرحلة التنفيذ } & \multicolumn{2}{|c|}{ مرحلة التخطيط } & \multicolumn{2}{|c|}{ مرحلة تحديد } & \multirow{2}{*}{ مستوى الوعى بمورد } \\
\hline$\%$ & العدد & $\%$ & العدد & $\%$ & العدد & $\%$ & العدد & $\%$ & العدد & \\
\hline 5.5 & 11 & 2.0 & 4 & 2.5 & 5 & 2.0 & 4 & 2.5 & 5 & مستوى منخفض \\
\hline 55.0 & 110 & 36.5 & 73 & 34.5 & 69 & 38.0 & 76 & 33.0 & 66 & مستوى متوسط \\
\hline 39.5 & 79 & 61.5 & 123 & 63.0 & 126 & 60.0 & 120 & 64.5 & 129 & مستوى مرتفع \\
\hline 100 & 200 & 100 & 200 & 100 & 200 & 100 & 200 & 100 & 200 & المجموع \\
\hline
\end{tabular}

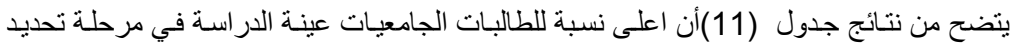

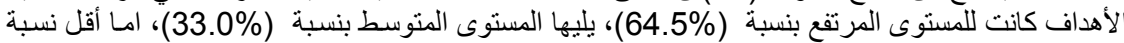

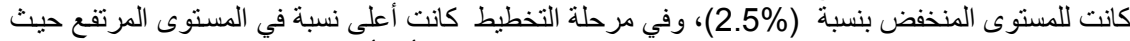

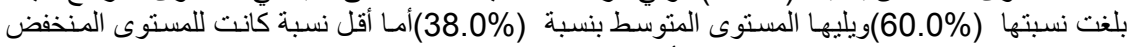

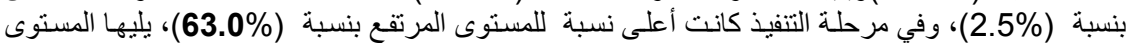

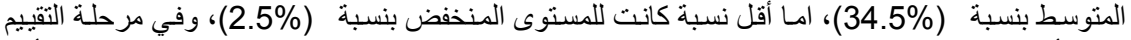

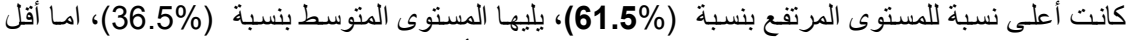

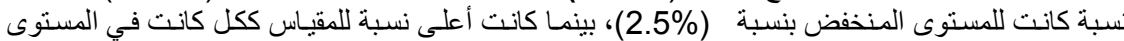

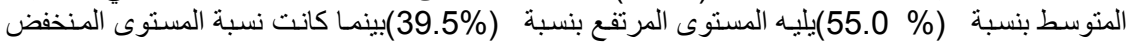

(5.5\%) .

اجابات الطالبات الجامعيات عينة الدراسة على عبارات الوعي بمورد الوقت :

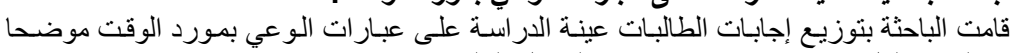

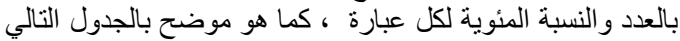

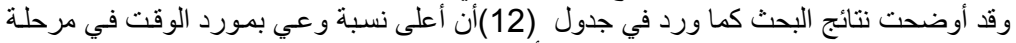

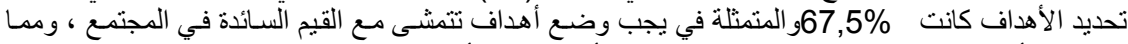

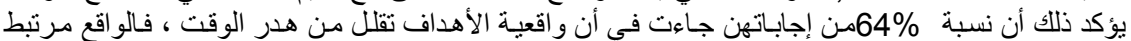

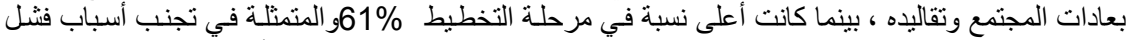

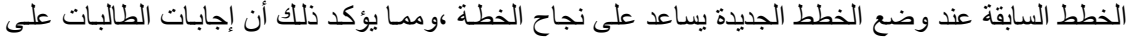

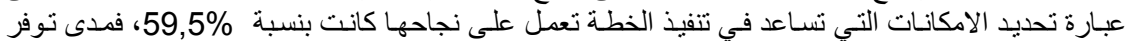

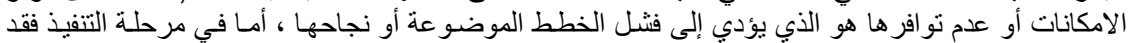

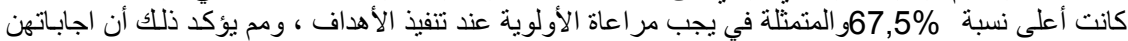

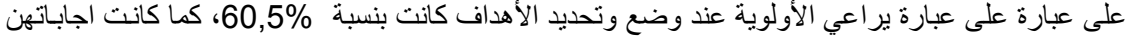




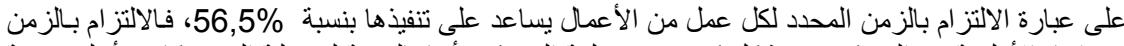

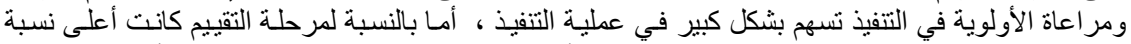

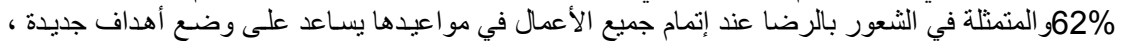

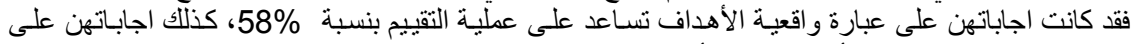

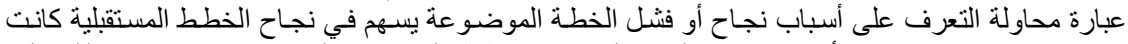

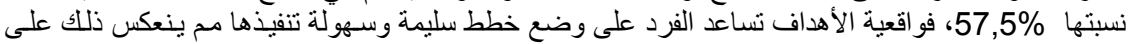

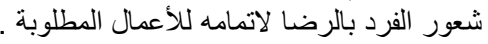


Rehan, E. R. et al. 
J. Agric. Econom. and Social Sci., Mansoura Univ., Vol.4 (6), June, 2013 
Rehan, E. R. et al.

جدول (13) توزيع طالبات المرحلة الجامعية عينة البحث تبعا لمستوى ممارستهن بمورد الوقت

\begin{tabular}{|c|c|c|c|c|c|c|c|c|c|c|}
\hline \multicolumn{2}{|c|}{ الدرجة الكلية } & \multicolumn{2}{|c|}{ مرحلة التقييم } & \multicolumn{2}{|c|}{ مرحلة التنفيذ } & \multicolumn{2}{|c|}{ مرحلة التخطيط } & \multicolumn{2}{|c|}{ مرحلة تحدافيد } & \multirow{2}{*}{ البولوقي } \\
\hline$\%$ & العدد & $\%$ & العدد & $\%$ & العدد & $\%$ & العدد & $\%$ & العدد & \\
\hline 2.0 & 4 & 8.0 & 16 & 3.5 & 7 & 6.5 & 13 & 4.5 & 9 & منخفض \\
\hline 42.0 & 84 & 45.5 & 91 & 36.5 & 73 & 36.5 & 73 & 35.5 & 71 & متوسط \\
\hline 56.0 & 112 & 46.5 & 93 & 60.0 & 120 & 57.0 & 114 & 60.0 & 120 & مرتفع \\
\hline 100 & 200 & 100 & 200 & 100 & 200 & 100 & 200 & 100 & 200 & المجموع \\
\hline
\end{tabular}

يتضح من جدول (13)أن مستوى ممارسة طالبـات المرحلة الجامعية عينة البحث بمورد الوقت

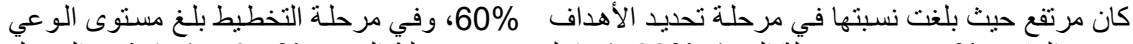

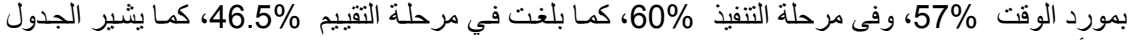

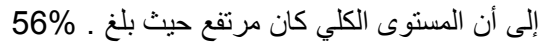

\begin{tabular}{|c|c|c|c|c|c|c|c|c|c|c|}
\hline \multirow{2}{*}{ الدلالة } & \multirow{2}{*}{ كا } & \multirow{2}{*}{$\tau$} & \multicolumn{2}{|c|}{ لا لا بحدث } & \multicolumn{2}{|c|}{ احيانًا } & \multicolumn{2}{|c|}{ غالبا } & \multirow{2}{*}{ 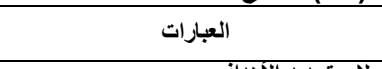 } & \\
\hline & & & $\%$ & s & $\%$ & ك & $\%$ & s & & \\
\hline & & & & & & & & & اولا :تحديد الاهداف & \\
\hline 0.001 & 114.79 & 2 & 4.5 & 9 & 29.5 & 59 & 66.0 & 132 & الوقت المناسب . الحسم بين البدائل واتخـاذ القرار في & \\
\hline 0.001 & 33.25 & 2 & 15.0 & 30 & 37.5 & 75 & 47.5 & 95 & 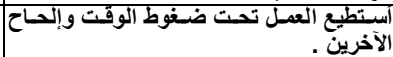 & \\
\hline 0.001 & 117.88 & 2 & 5.0 & 10 & 28.0 & 56 & 67.0 & 134 & بدقة وسهولة الإخرين في عملي يؤدي إلى إنهائها & 3- \\
\hline 0.001 & 31.72 & 2 & 15.0 & 30 & 39.0 & 78 & 46.0 & 92 & 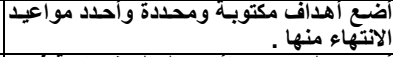 & 4- \\
\hline 0.001 & 54.61 & 2 & 11.0 & 22 & 35.5 & 71 & 53.5 & 107 & 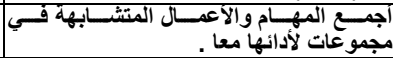 & 5- \\
\hline 0.001 & $\begin{array}{ll}13.81 \\
22.75\end{array}$ & $\frac{2}{2}$ & \begin{tabular}{|l|}
21.0 \\
17.5
\end{tabular} & $\frac{42}{35}$ & $\begin{array}{l}40.5 \\
40.0\end{array}$ & $\begin{array}{l}81 \\
80\end{array}$ & $\begin{array}{l}38.5 \\
42.5\end{array}$ & $\begin{array}{l}77 \\
85\end{array}$ & 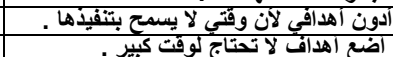 & 6- \\
\hline غغير دالة & 1.09 & 2 & 33.0 & 66 & 36.5 & 73 & 30.5 & 61 & 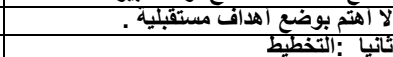 & \\
\hline 0.001 & 42.19 & 2 & 14.5 & 29 & 33.5 & 67 & 52.0 & 104 & دقةّ وغناية . أو جلول زمني لتحقيق أعمالي بكل & \\
\hline 0.001 & 38.68 & 2 & 13.0 & 26 & 40.0 & 80 & 47.0 & 94 & 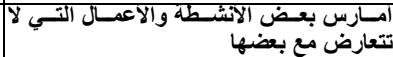 & 10- \\
\hline 0.001 & 66.37 & 2 & 7.5 & 15 & 39.0 & 78 & 53.5 & 107 & اهتم بالزمن أمحدد لكل عمل من الاعمال . . & $11-$ \\
\hline 0.001 & 51.43 & 2 & 10.0 & 20 & 40.5 & 81 & 49.5 & 99 & 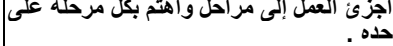 & 12- \\
\hline 0.001 & 71.47 & 2 & 7.5 & 15 & 36.5 & 73 & 56.0 & 112 & واضع أولو & 13- \\
\hline 0. & 14.77 & 2 & 21.5 & 43 & 35.0 & 70 & 43.5 & 87 & & \\
\hline 0.001 & 19 & 2 & 22.0 & 44 & 31.0 & 62 & 47.0 & 94 & اضع جذول للمذاكرة . . & 15- \\
\hline $\begin{array}{ll}0.01 \\
0.001 \\
\end{array}$ & \begin{tabular}{|l|}
13.21 \\
19.96 \\
\end{tabular} & $\begin{array}{l}2 \\
2\end{array}$ & \begin{tabular}{|l|}
21.5 \\
19.0
\end{tabular} & $\begin{array}{l}43 \\
38\end{array}$ & $\begin{array}{l}41.5 \\
44.0\end{array}$ & $\begin{array}{l}83 \\
88\end{array}$ & $\begin{array}{l}37.0 \\
37.0\end{array}$ & $\begin{array}{l}74 \\
74\end{array}$ & 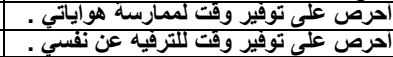 & $\begin{array}{l}16- \\
17-\end{array}$ \\
\hline & & & & & & & & & i & \\
\hline 0.001 & 39.64 & 2 & 13.0 & 26 & 39.0 & 78 & 48.0 & 96 & انجاز العقل المطلوب لاطول فترة ممكنـة امسلا في & 18 \\
\hline 0.001 & 42.97 & 2 & 11.5 & 23 & 43.5 & 87 & 45.0 & 90 & 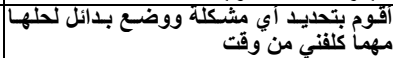 & 9 \\
\hline 0.001 & 61.390 & 2 & 8.0 & 16 & 51.5 & 103 & 40.5 & 81 & لادي المهارَات الكافِيه للقيام باي عمل . & 20 \\
\hline 0.001 & 64.99 & 2 & 9.5 & 19 & 34.5 & 69 & 56.0 & 112 & 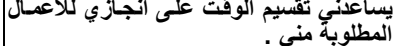 & \\
\hline 0.001 & \begin{tabular}{|l|}
64.87 \\
\end{tabular} & 2 & 10.0 & 20 & 33.5 & 67 & 56.5 & 113 & اراعي حضور محاضراتي في مواعيدها & 22 \\
\hline$\pi$ & & 2 & & 26 & & 80 & & 94 & التزّم بمواعياِي مهما كاتت الظروفت & 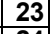 \\
\hline 0.001 & 18.61 & 2 & 19.0 & 38 & 41.5 & 83 & 39.5 & 79 & التزّم بجدول مذَكَتَّي & 24 \\
\hline 0. & 10.69 & 2 & 23.0 & 46 & 35.5 & 71 & 41.5 & 83 & عليها . أرتباتي باستمرار حتى يسـهل الحصول| & 25 \\
\hline 0.05 & 8.32 & 2 & 24.0 & 48 & 36.0 & 72 & 40.0 & 80 & 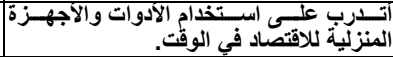 & 26 \\
\hline 0.001 & 66.52 & 2 & 9.0 & 18 & 35.0 & 70 & 56.0 & 112 & 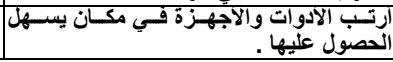 & 27 \\
\hline
\end{tabular}


تابع جدول (14) توزيع الطالبات الجامعيات عينة الدراسة وفقا لاجاباتهن على عبارات ممارسة مورد

\begin{tabular}{|c|c|c|c|c|c|c|c|c|c|c|}
\hline \multirow{2}{*}{ الدلالة } & \multirow[b]{2}{*}{25} & \multirow{2}{*}{$\tau$} & \multicolumn{2}{|c|}{ لا يحدث } & \multicolumn{2}{|c|}{ أحيانا } & \multicolumn{2}{|c|}{ غالبا } & \multirow[b]{2}{*}{ العبارات } & \multirow[b]{2}{*}{ s } \\
\hline & & & $\%$ & S & $\%$ & s & $\%$ & ك & & \\
\hline & & & & & & & & & رابعا : التقييم & \\
\hline 0.001 & 43.75 & 2 & 12.5 & 25 & 37.5 & 75 & 50.0 & 100 & 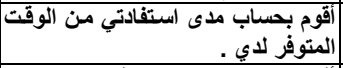 & 28 \\
\hline 0.001 & 32.83 & 2 & 14.5 & 29 & 40.0 & 80 & 45.5 & 91 & |أقوم بحساب الأعمال . & 29 \\
\hline 0.001 & 24.49 & 2 & 17.0 & 34 & 43.5 & 87 & 39.5 & 79 & 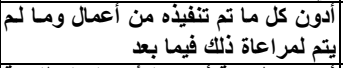 & 30 \\
\hline 0.001 & 36.13 & 2 & 15.0 & 30 & 35.5 & 71 & 49.5 & 99 & |مني لإمكانية تحسينة أدائي للأعمال المطلوبـة & 31 \\
\hline 0.001 & 38.71 & 2 & 14.0 & 28 & 36.5 & 73 & 49.5 & 99 & 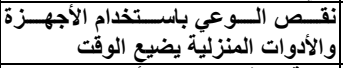 & 32 \\
\hline 0.001 & 39.97 & 2 & 12.5 & 25 & 41.0 & 82 & 46.5 & 93 & 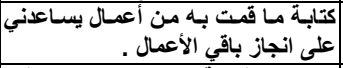 & 33 \\
\hline 0.001 & 74.89 & 2 & 4.5 & 9 & 47.0 & 94 & 48.5 & 97 & 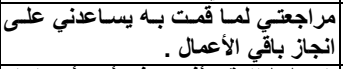 & 34 \\
\hline 0.001 & 50.08 & 2 & 10.0 & 20 & 42.0 & 84 & 48.0 & 96 & |أكن أقطّم بها للوقت أفادني في أداء أعمال لم| & 35 \\
\hline غير دالة & 5.23 & 2 & 27.5 & 55 & 40.5 & 81 & 32.0 & 64 & 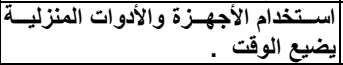 & 36 \\
\hline
\end{tabular}

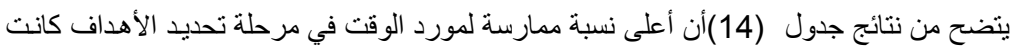

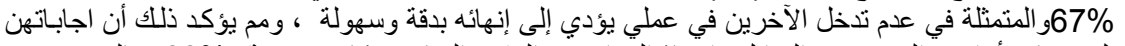

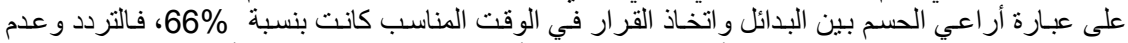

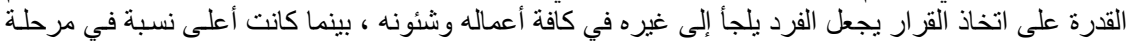

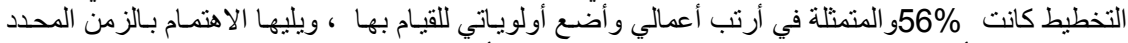

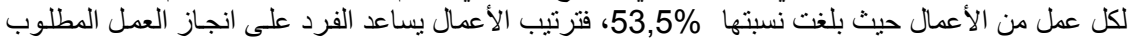

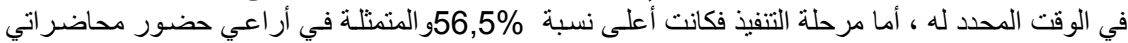

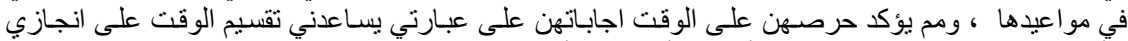

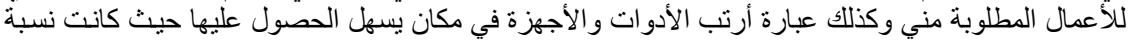

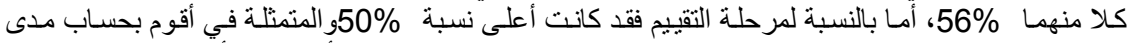

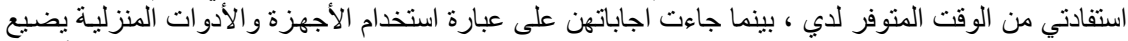

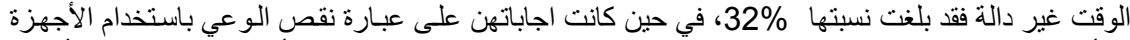

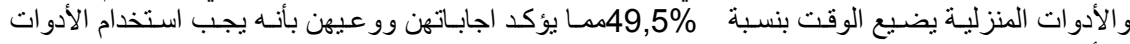

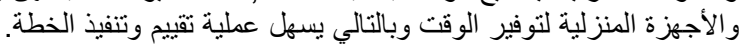


Rehan, E. R. et al. 


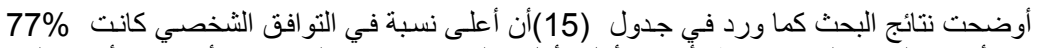

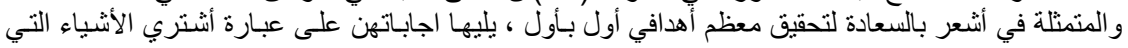

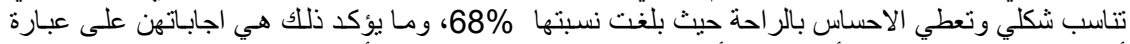

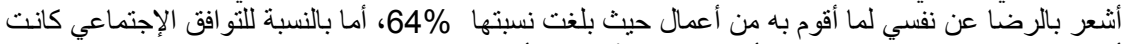

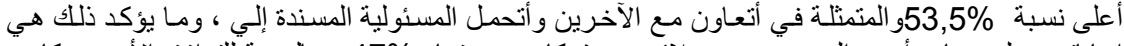

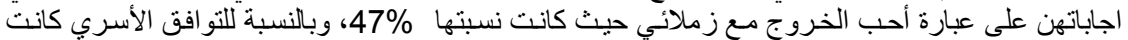

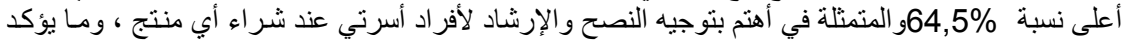

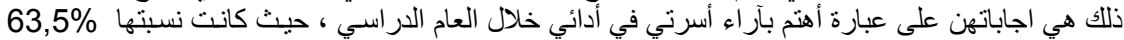

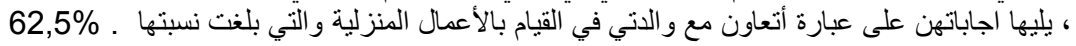

جدول (16) توزيع طالبات المرحلة الجامعية عينة البحث تبعا لمستوى أبعاد التوافق لايهن

\begin{tabular}{|c|c|c|c|c|c|c|c|c|}
\hline \multicolumn{2}{|c|}{ الدرجة الكلية } & \multicolumn{2}{|c|}{ التوافق الأسري } & \multicolumn{2}{|c|}{ التوافق الإجتماعي } & \multicolumn{2}{|c|}{ التوافق الشخصي } & \multirow{2}{*}{ مستوى أبعاد } \\
\hline$\%$ & العدد & $\%$ & العدد & $\%$ & العدد & $\%$ & العدد & \\
\hline 2.5 & 5 & 2.5 & 5 & 20.5 & 41 & 9.0 & 18 & منخفض \\
\hline 34.5 & 69 & 23.0 & 46 & 49.5 & 99 & 68.5 & 137 & متوسط \\
\hline 63.0 & 126 & 74.5 & 149 & 30.0 & 60 & 22.5 & 45 & مرتفع \\
\hline 100 & 200 & 100 & 200 & 100 & 200 & 100 & 200 & المجموع \\
\hline
\end{tabular}

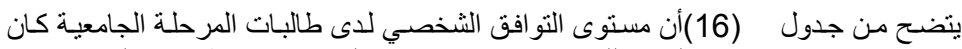

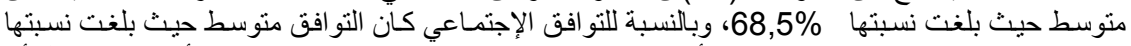

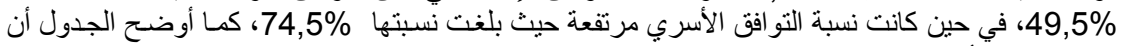

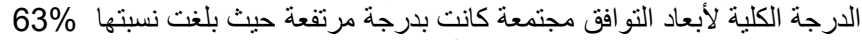

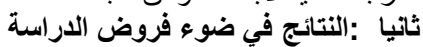

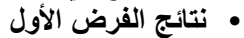

"توجد علاقة ذات دلالة إحصائية بين و عي طالبات المرحلة الجامعية نحو استخدام مورد الوقت و أبعاد التو افق "لديهن . لوجن وللتحقق من صحة هذا الفرض قامت الباحثة باستخدام معامل ارتباط بيرسون بين وكئ وعي طالبات

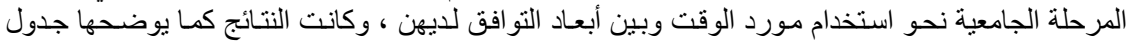

(17) .

جدول (17) يوضـح قيم ارتبـاط بيرسون بين وعي طالبات المرحلة الجامعية نحو استخدام مورد الوقت وأبعاد التوافق لإيهن

\begin{tabular}{|c|c|c|c|c|c|}
\hline الجامعية طالبات المرد الوقلة & رابعا :التقييم & ثالثا :التنفيذ & ثانيا :التخطيط & |أولا :تحديد الأهداف & التو افقى لاى الطالبات الوقات \\
\hline $0.189^{\star *}$ & 0.134 & $0.214^{* *}$ & 0.083 & $0.160^{*}$ & اولا :التوافق الثخصي \\
\hline 0.006 & -0.039 & $-0.007-$ & 0.055 & 0.018 & تُانيا :التوافق الاجتماعي \\
\hline $0.243^{\star *}$ & 0.098 & $0.290^{\star \star}$ & $0.236^{\star \star}$ & $0.151^{*}$ & 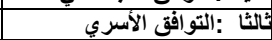 \\
\hline $0.222^{* *}$ & 0.099 & $0.256^{* *}$ & $0.193^{* *}$ & $0.159^{*}$ & 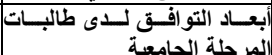 \\
\hline
\end{tabular}

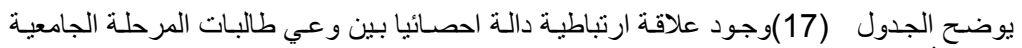

لمورد الوقت وبين أبعاد التو افق لديهن حيث كانت قيمة ارتباط بيرسون

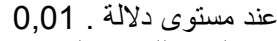

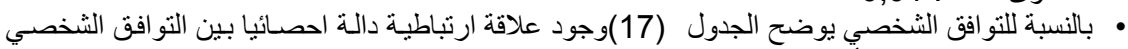

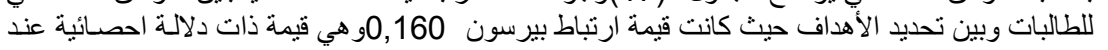

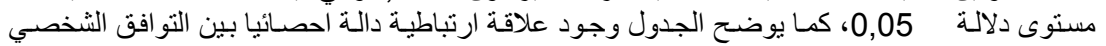

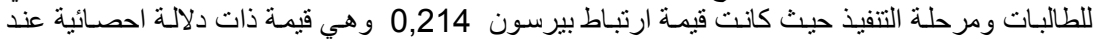


Rehan, E. R. et al.

مستوى دلالة مان 0,01، كذنك يوضح الجدول عدم وجود علاقة ارتباطية بين التوافق الثخصي ومرحلة

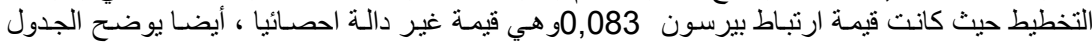

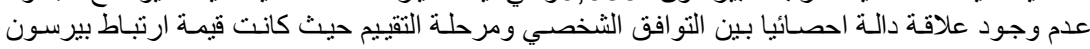
م0,134و هي قيمة غير دالة الحصائيا. .

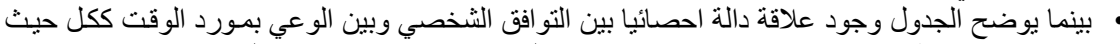

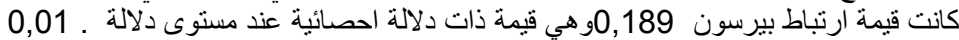

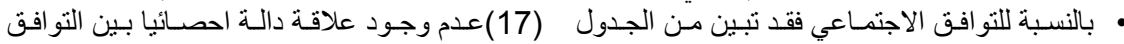
الاجتماعي ووعى الطالبات بمورد الوقت حيث كانت قيمة ارتباط بيرسون 0,006و هي قيمة غير دالة التئ

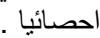

• بالنسبة للتو افق الأسري يوضح الجدول (17)وجود علاقة دالة احصائيا بين التو افق الأسري وبين وعي

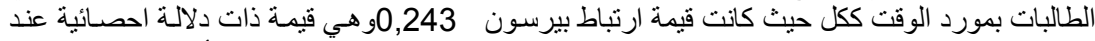

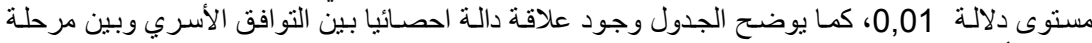

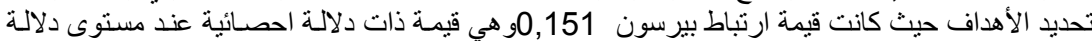

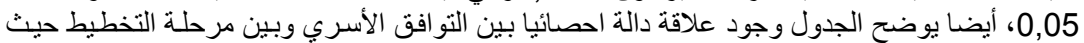

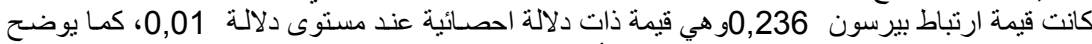

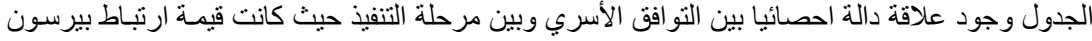

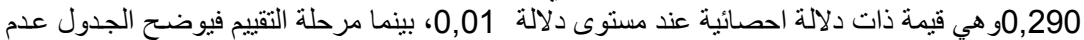

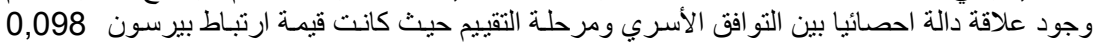

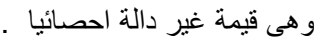
• كما يوضح الجدول وجود علاقة دالة احصائيا بين أبعاد التو افق ككل وبين مرحلة تحديد الأهداف حيث

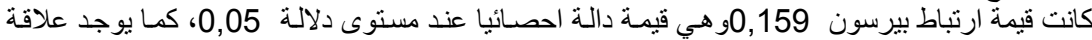

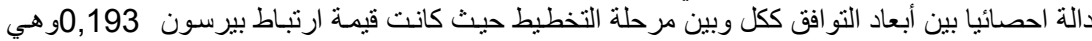

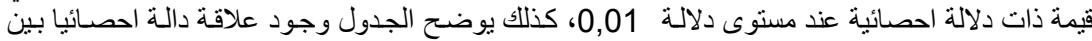

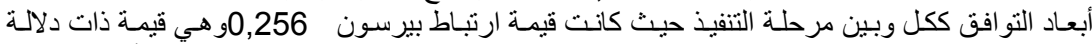

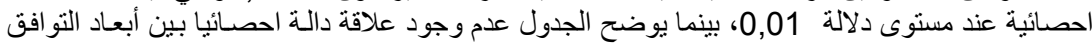

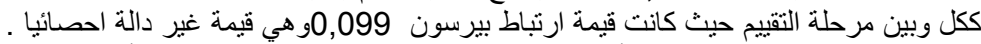

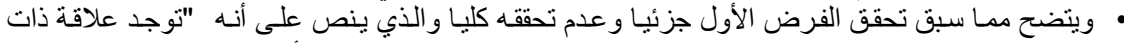

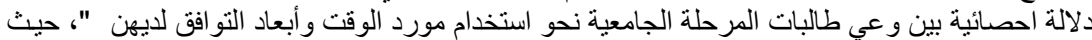

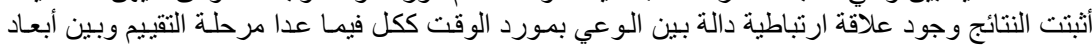

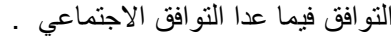

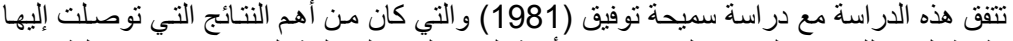

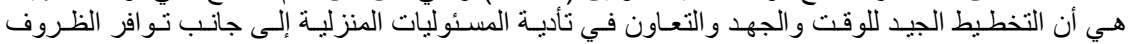

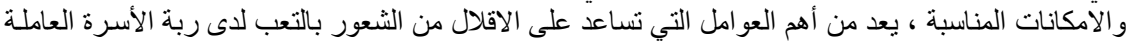

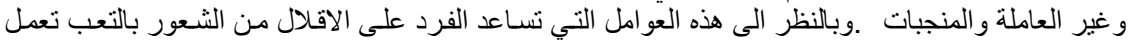
كذلك على تو افقه الثخصي و والأسري .

ولكن تختلف ألدر استة الحالية مع دراسة سميحة توفيق (1981) في ان الأولى تم تطبيقها على الكى

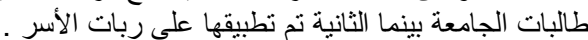

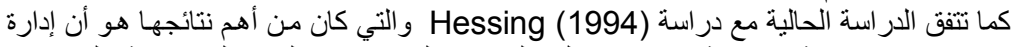

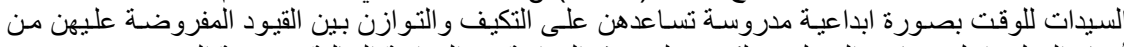

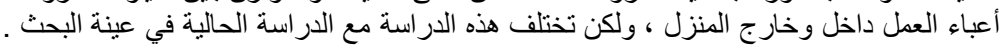

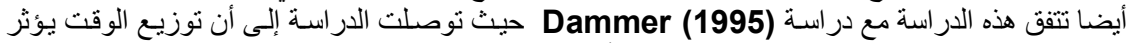

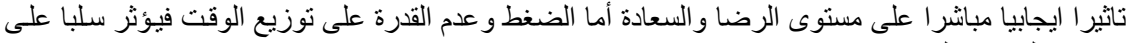

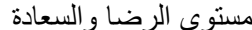

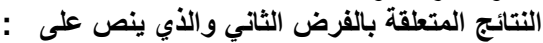

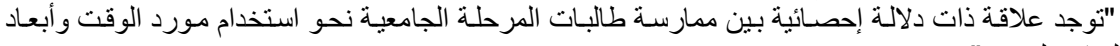




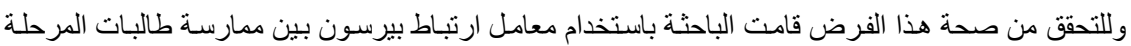

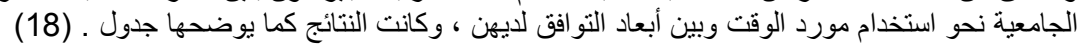

جدول (18) يوضع قيم ارتباط بيرسون بين ممارسـة طالبـات المرحلة الجامعيـة نحو استخدام مورد الوقت وابعاد التوافق لايهن

\begin{tabular}{|c|c|c|c|c|c|}
\hline ممارسة طالبات المرحلة & رابعا :التقييم & ثالثا :التنفيذ & ثانيا :التخطيط & أولا :تحديد & التوافو لمورد الوقت الطالبات الطالبات \\
\hline $0.163^{*}$ & 0.105 & $0.170 *$ & $0.186^{\star *}$ & $-0.044-$ & ولا :التوافقى الثخصي \\
\hline 0.015 & 0.067 & 0.003 & 0.015 & $-0.056-$ & كانيا :التوافق الاجتماعي \\
\hline $0.172^{*}$ & 0.105 & $0.191^{* *}$ & 0.118 & 0.057 & لُالثا :التوافق الأسري \\
\hline $0.173^{*}$ & 0.126 & $0.183^{\star *}$ & $0.148^{*}$ & $-0.001-$ & 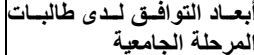 \\
\hline
\end{tabular}

يوضح الجدول (18)وجود علاقة ارتباطية دالة احصـائيا بين ممارسـة طالبات المرحلة الجامعية

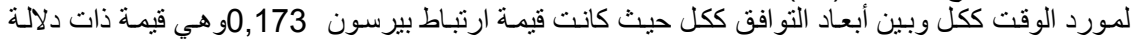

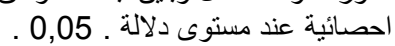

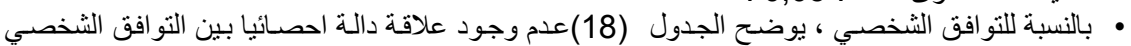

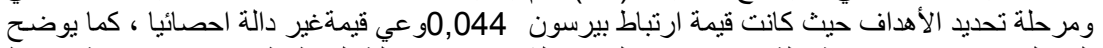

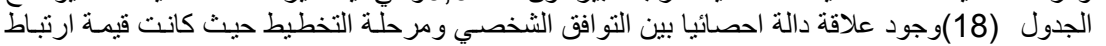

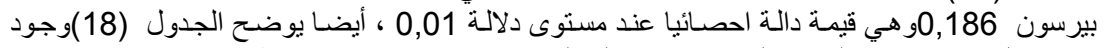

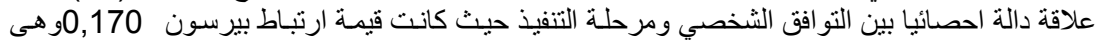

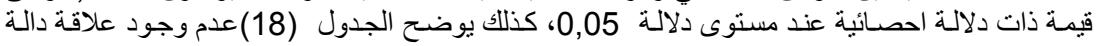

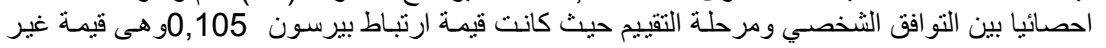

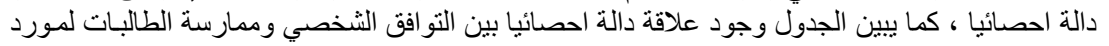

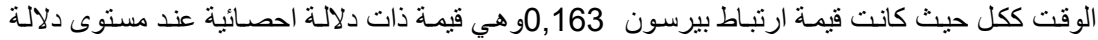
0,05 • بالنسبة للتو افق الاجتمـاعي يوضـح الجدول (18)عدم وجود علاقة دالة احصـائيا بين التو افق الاجتمـاعي

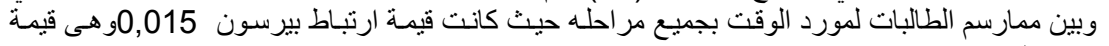
غير دالة احصائيا . بالبات

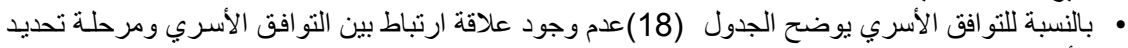

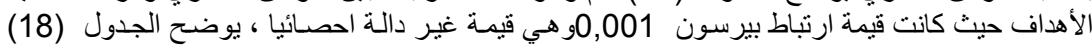

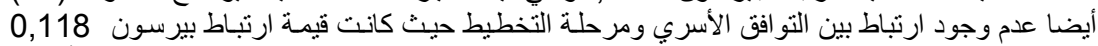

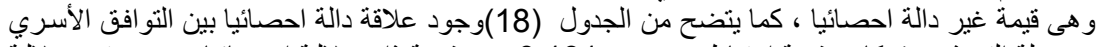

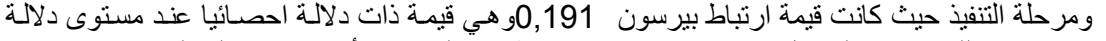

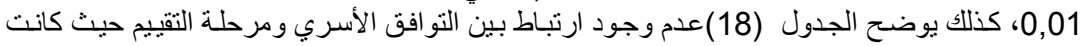

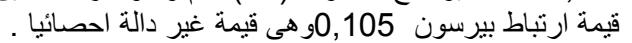

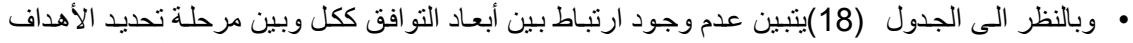

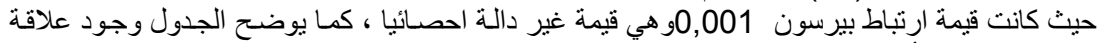

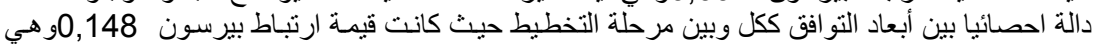

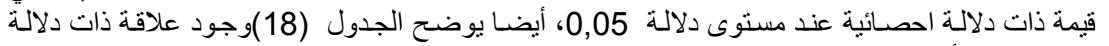

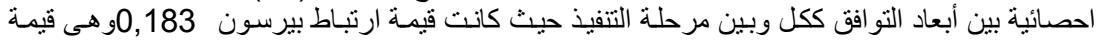

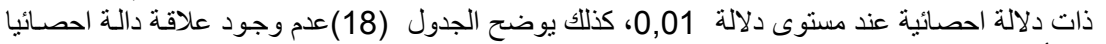
بين أبعاد التو افق ككل وبين مرحلة التقييم حيث كانت

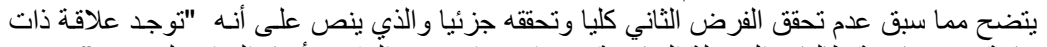

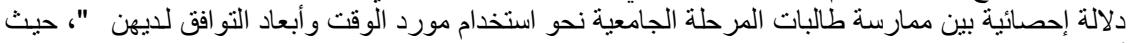

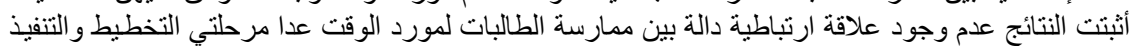

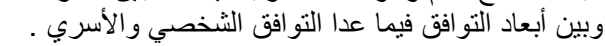


Rehan, E. R. et al.

النتائج المتعلقة بالفرض الثالث والأي ينص على : إلتص

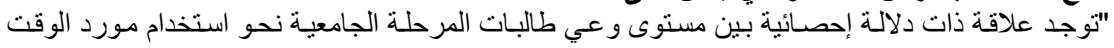

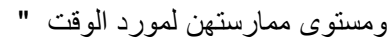

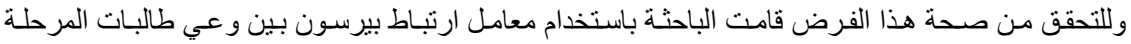

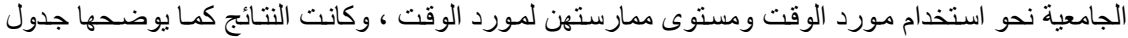

جدول (19) يوضح قيم ارتباط بيرسون بين مستوى وعي طالبات المرحلة الجامعية نحو استخدام مورد

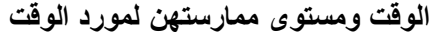

\begin{tabular}{|c|c|c|c|c|c|}
\hline وعى طالبات المرحلة الجامعية & رابعا :التقيييم & ثالثا :التنفيذ & ثانيا :التخطيط & أولالاف :تحديد & 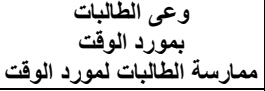 \\
\hline $0.420^{* *}$ & $0.286^{* *}$ & $0.263^{* *}$ & $0.402^{\star *}$ & $0.384^{* *}$ & |ولا :تحديد الأهداف \\
\hline $0.350^{* *}$ & $0.245^{\star *}$ & $0.251^{* *}$ & $0.327^{\star *}$ & $0.288^{\star *}$ & بانيا :التخطيط \\
\hline $0.325^{\star *}$ & $0.292^{* *}$ & $0.234^{* *}$ & $0.207^{\star *}$ & $0.284^{\star *}$ & اُّالثا :التنفيذ \\
\hline $0.390^{\star *}$ & $0.367^{* *}$ & $0.230^{* *}$ & $0.282^{\star *}$ & $0.342^{\star *}$ & رابعا :التقييم \\
\hline $0.515^{\star *}$ & $0.416^{* *}$ & $0.342^{\star *}$ & $0.418^{\star *}$ & $0.449^{\star *}$ & 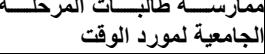 \\
\hline
\end{tabular}

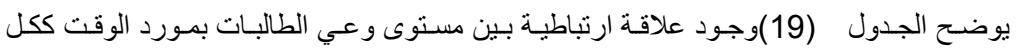

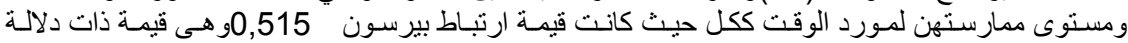

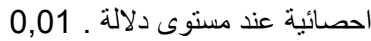

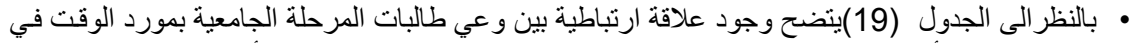

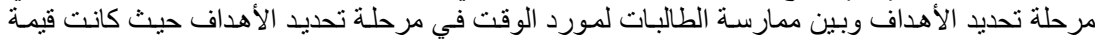

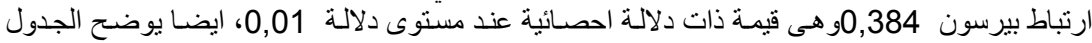

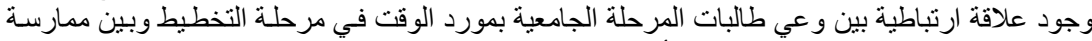

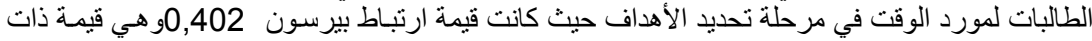

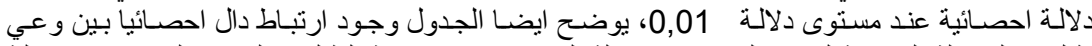

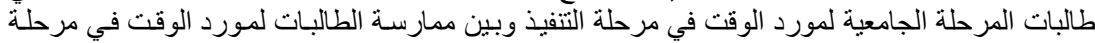

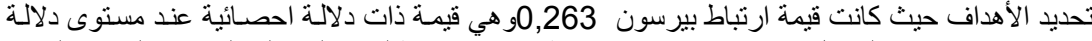

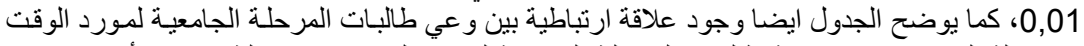

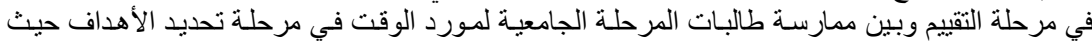

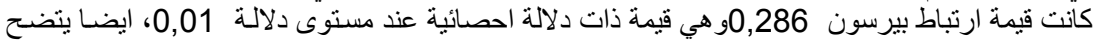

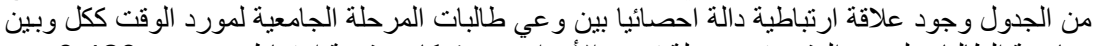

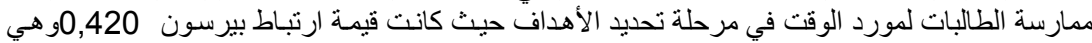

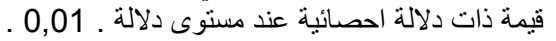

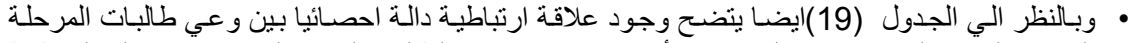

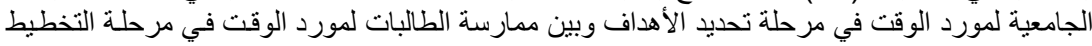

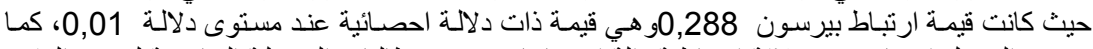

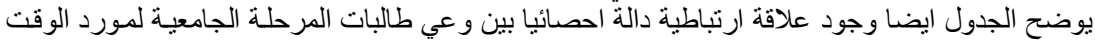

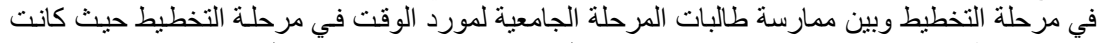

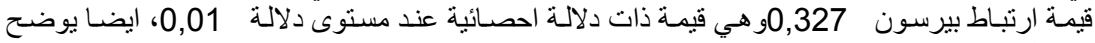

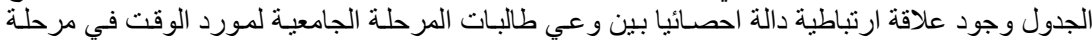

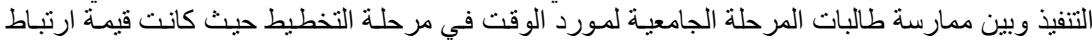

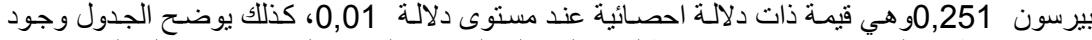

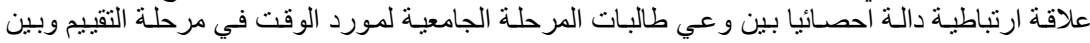

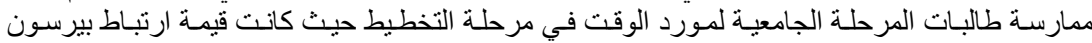

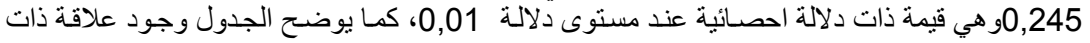




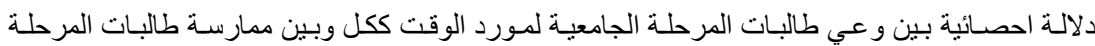

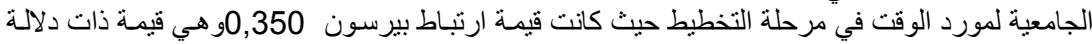

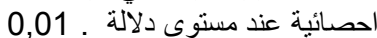

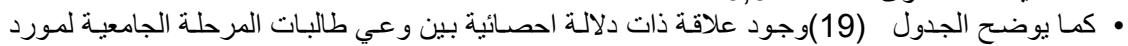

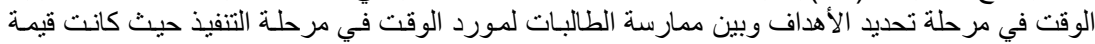

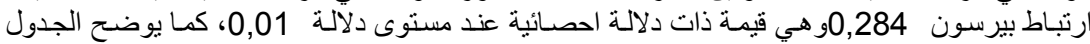

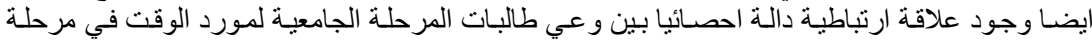

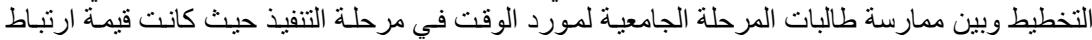

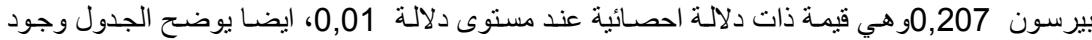

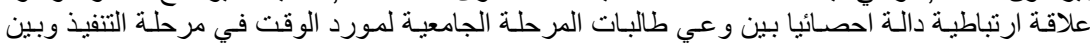

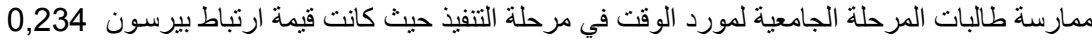

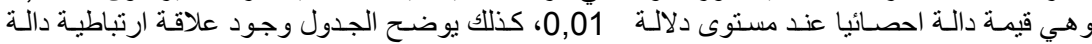

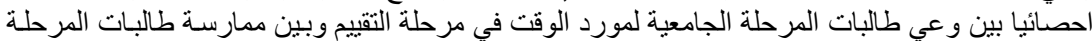

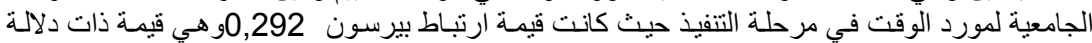

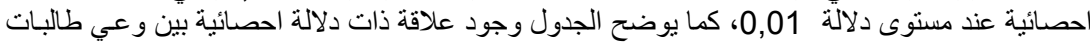

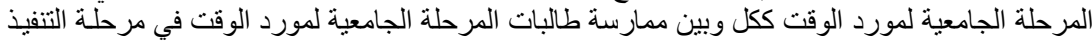

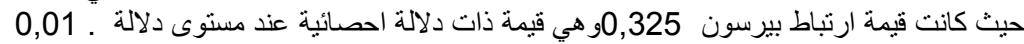

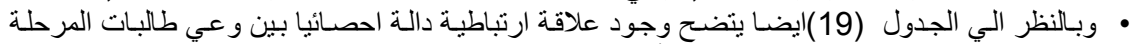

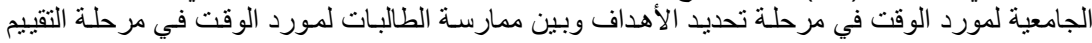

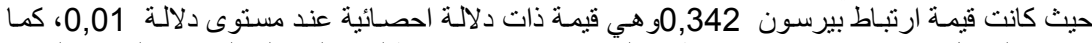

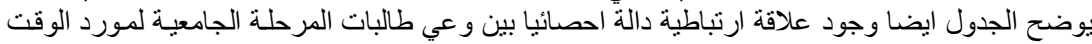

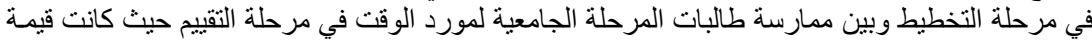

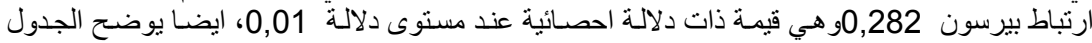

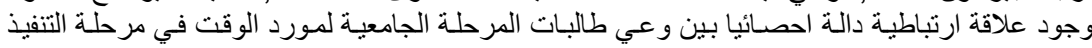

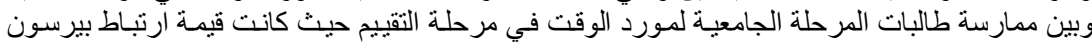

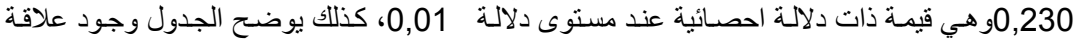

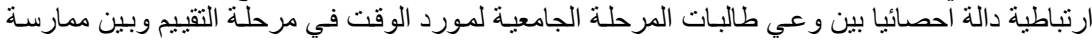

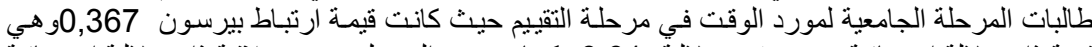

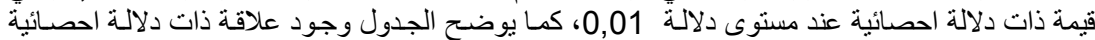

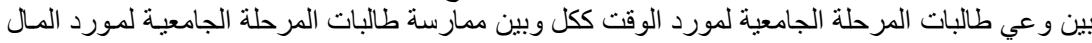

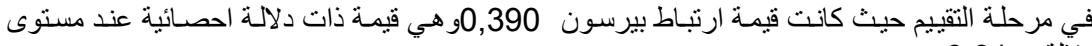

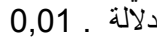

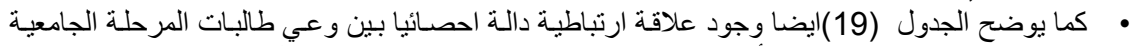

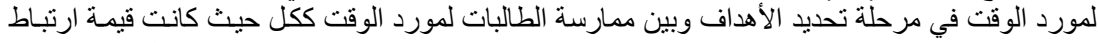

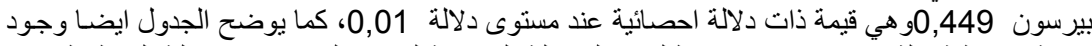

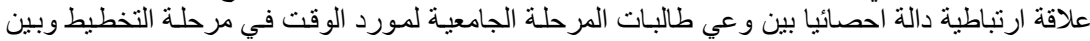

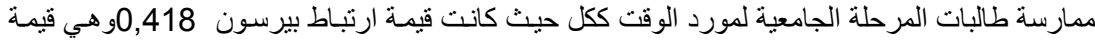

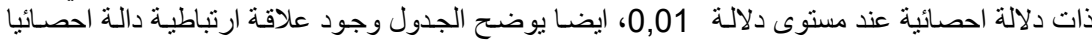

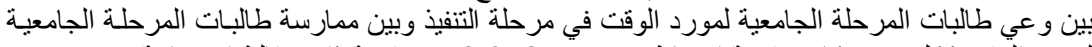

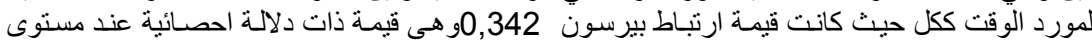

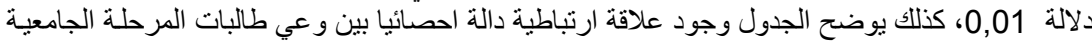

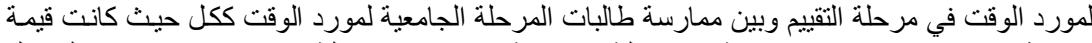

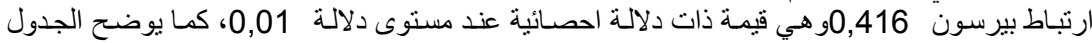

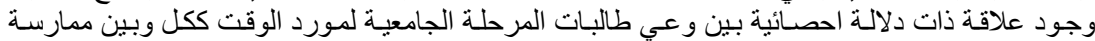

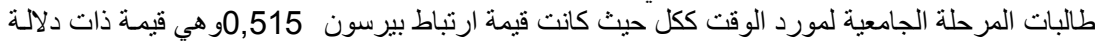

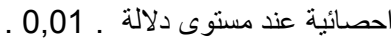


Rehan, E. R. et al.

ويتضح مما سبق تحقق الفرض الثالث كليا و الذي ينص على انه "توجد علاقة ذات دلالة إحصائية

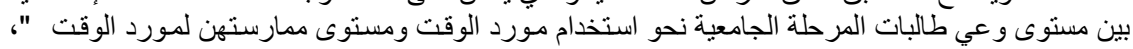

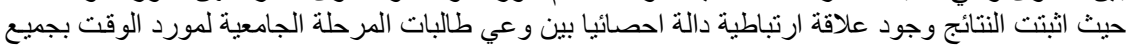

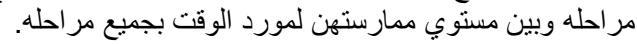

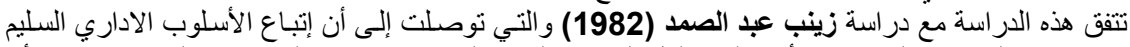

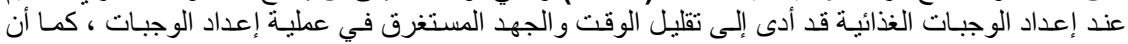

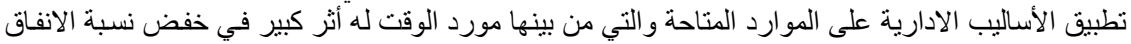

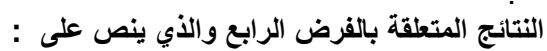

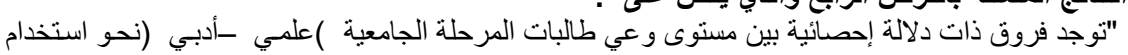
مورد الوقت فوقت وللتحقق من صحة الفرض تم حساب المتوسطات والانحر افات المعيارية وقيمة ت لحساب دلالالة

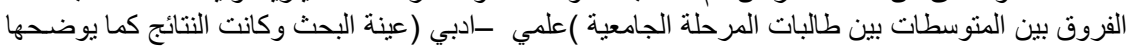

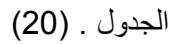
جدول (20) قيمة )ت (ومستوى دلالتها الإحصائية للفروق بين متوسطات درجات مستوى وعي الطالبات عينة البحث )علمي -أدبي (نحو استخدام مورد الوقيت الوبري

\begin{tabular}{|c|c|c|c|c|c|c|c|}
\hline الدلالة & $\tau^{2}$ & $ت$ & الانحراف المعياري & المتوسط & العدد & التخصص & البعد \\
\hline \multirow{2}{*}{ غير دالة } & \multirow{2}{*}{198} & \multirow{2}{*}{1.590} & 5.759 & 39.28 & 99 & علمي & \multirow{2}{*}{ أولا :تحديد الأهداف } \\
\hline & & & 5.474 & 38.02 & 101 & |أدبي & \\
\hline \multirow{2}{*}{ غير دالة } & \multirow{2}{*}{198} & \multirow{2}{*}{1.562} & 5.713 & 38.25 & 99 & علمي & \multirow{2}{*}{ |أنيا :التخطيط } \\
\hline & & & 4.886 & 37.08 & 101 & |أدبي & \\
\hline \multirow{2}{*}{0.05} & \multirow{2}{*}{198} & \multirow{2}{*}{2.562} & 5.217 & 39.10 & 99 & علمي & \multirow{2}{*}{ الثالثا :التنقيذ } \\
\hline & & & 6.065 & 37.05 & 101 & |أدبي & \\
\hline \multirow{2}{*}{ غير دالة } & \multirow{2}{*}{198} & \multirow{2}{*}{0.426} & 6.124 & 41.49 & 99 & علمي & \multirow{2}{*}{ :التقييم } \\
\hline & & & 6.366 & 41.12 & 101 & |ادبي & \\
\hline \multirow{2}{*}{ |غير دالة } & \multirow{2}{*}{198} & \multirow{2}{*}{1.915} & 18.628 & 158.13 & 99 & علمي & طال \\
\hline & & & 17.275 & 153.27 & 101 & |إبّ & لَّ بمورد الوقت \\
\hline
\end{tabular}

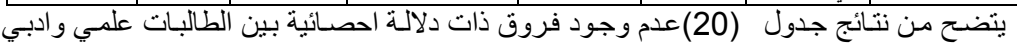

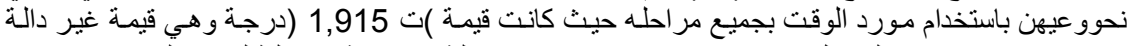

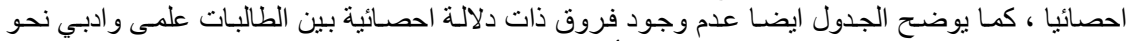

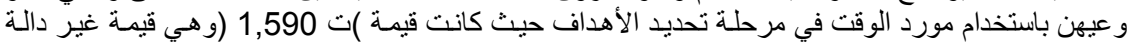

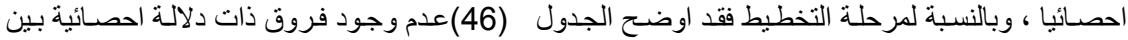

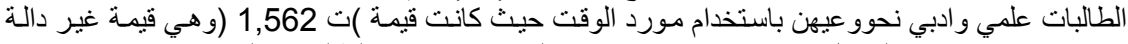

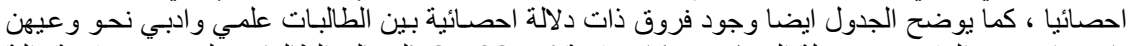

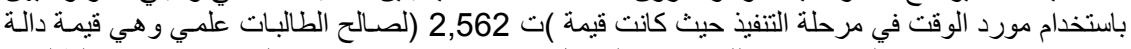

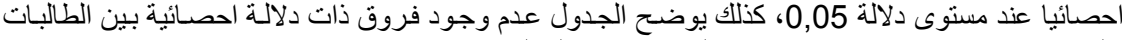
علمى و ادبي نحوو عيهن باستخدام مورد الوقت في مرحلة التقييم حيث كانت قيمة ) ت 0,426 (وهي قيمة غير

ومما سبق يتضح عدم تحقق الفرض الرابع كليا وتحققه جزئيا في مرحلة التنفيذ .

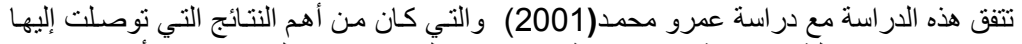

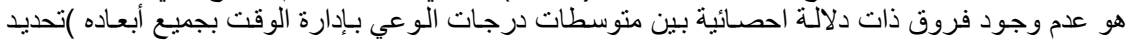

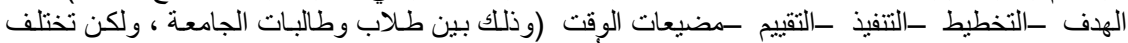

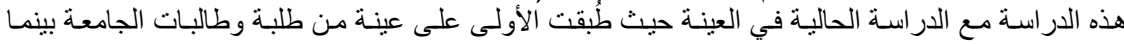

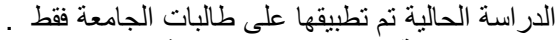

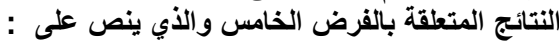

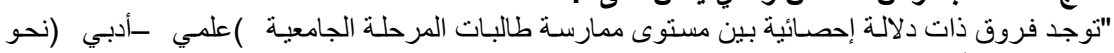

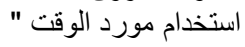


وللتحقق من صحة الفرض نم حسـاب المتوسطات والانحر افـات المعياريـة وقيمـة ت لحسباب دلالية

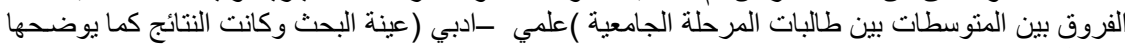

جدول (21)قيمة )ت (ومستوى دلالتها الإحصائية للفروق بين متوسطات درجات مستوى ممارسـة الطالبات

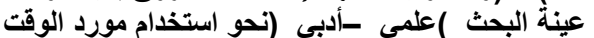

\begin{tabular}{|c|c|c|c|c|c|c|c|}
\hline الدلالة & $\tau^{2}$ & $ت$ & الانحراف المعياري & المنتوسط & العدد & التخصص & البعد \\
\hline \multirow{2}{*}{ | غير دالة } & 198 & 0.933 & 2.908 & 18.93 & 99 & علمي & \multirow{2}{*}{ |فولا :تحديد الأهداف } \\
\hline & & & 2.617 & 18.56 & 101 & أدبي & \\
\hline \multirow{2}{*}{ |غير دالة } & \multirow{2}{*}{198} & \multirow{2}{*}{1.508} & 3.855 & 21.28 & 99 & علمي & \multirow{2}{*}{ لُانيا :التخطيط } \\
\hline & & & 3.994 & 20.45 & 101 & |دببي & \\
\hline \multirow{2}{*}{0.01} & \multirow{2}{*}{198} & \multirow{2}{*}{2.767} & 3.704 & 24.05 & 99 & علمي & \multirow{2}{*}{ كالثا :التنفيذ } \\
\hline & & & 3.887 & 22.56 & 101 & |دببي & \\
\hline \multirow{2}{*}{ | غير دالة } & \multirow{2}{*}{198} & \multirow{2}{*}{0.551} & 3.653 & 20.59 & 99 & علمي & \multirow{2}{*}{ |رابعا :التقييم } \\
\hline & & & 3.421 & 20.86 & 101 & |دببي & \\
\hline \multirow{2}{*}{ غير دالة } & \multirow{2}{*}{198} & \multirow{2}{*}{1.709} & 10.283 & 84.85 & 99 & علمي & \multirow{2}{*}{ |لجمامعية بموردة طالبـات المرقت } \\
\hline & & & 9.684 & 82.44 & 101 & |أدبي & \\
\hline
\end{tabular}

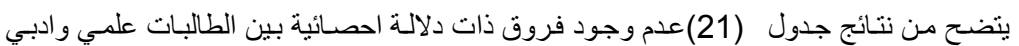

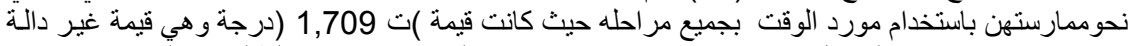

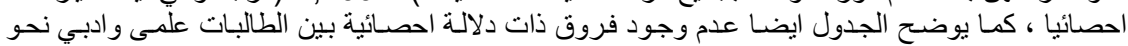

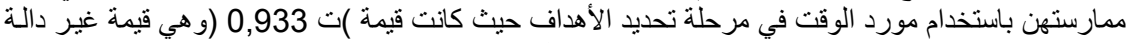

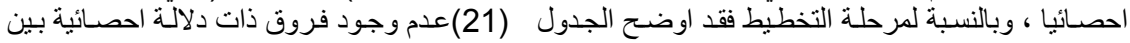

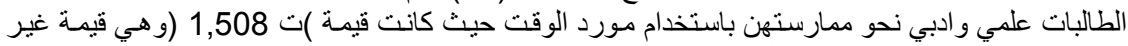

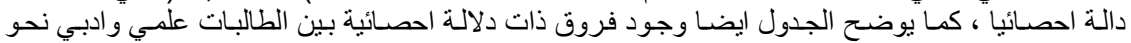

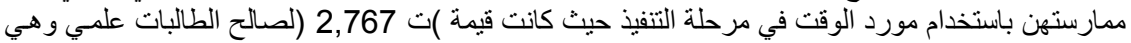

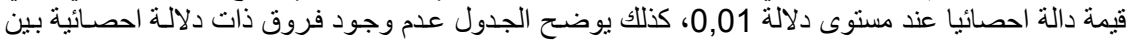

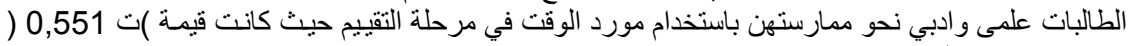
و وهي قيمة غير دالة احصائيا . ومماً سبق يتضح عدم تحقق الفرض الخامس كليا وتحققه جزئيا في مرحلة التنفيذ . .

ملخص لأهم نتائج الاراسة

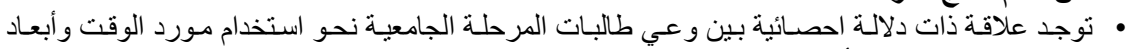

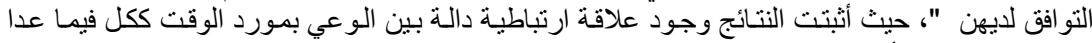

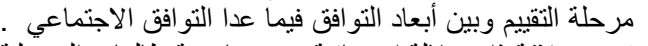

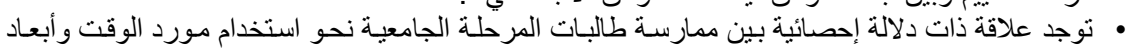

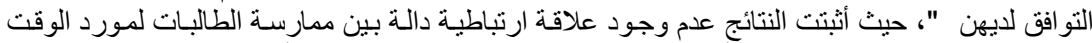

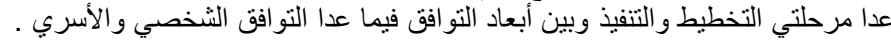

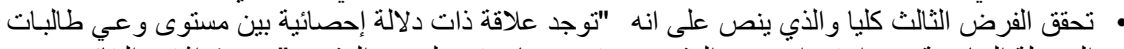

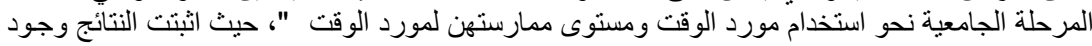

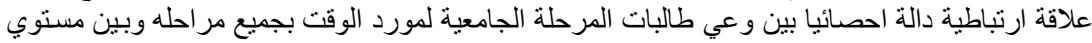

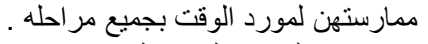

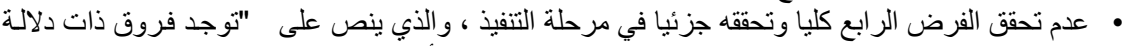

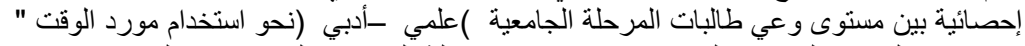

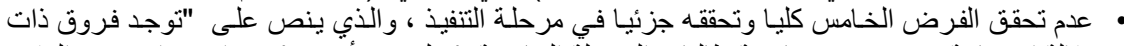

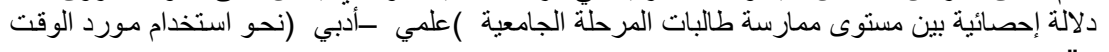


Rehan, E. R. et al.

• أهمية توفير دورات وبر امج تدرييية للطالبـات الجامعيات على كيفية إدارة وقتهن وفقا مـع مـا يناسب

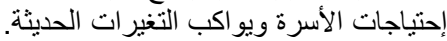
• أهمية إدخال بعض مناهج إدارة المنزل كإدارة مورد الوقت ، في مختلف التخصصات.

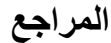

ا. إحسان ألبقلي ، دريـة أمين " : (2002) التخطيط والإدارة في الاقتصـاد المنزلي " ، مكتبة الأنجلو

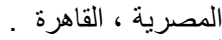

ז. أحمد إسماعيل حجى" : (1997) الإدارة التعليمية والإدارة المدرسية ،القاهرة ، دار الفكر العربي . r. ب. المعجم الوجيز (2002) ع. أنور محمد الثرقاوي " : (1998) التعلم) نظريات وتطبيقات " ( ، الطبعة الخامسـة ، مكتبـة الأنجلو المصرية ، القاهرة.

ه. إيزيس نوار، سهير نور ، منى بركات " : (1992) الاقتصاد الاستهلاكي الأسري ، قسم الاقتصاد المنزلي

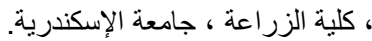

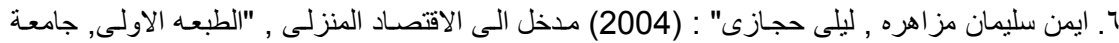

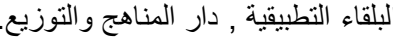

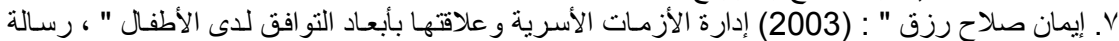

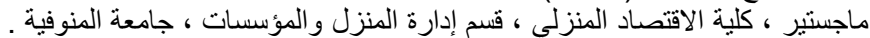

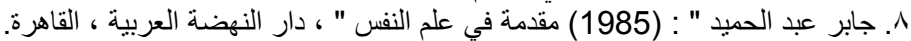

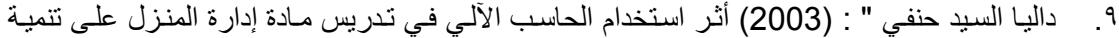

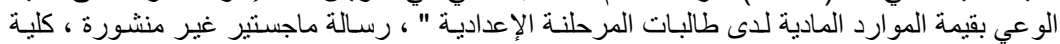

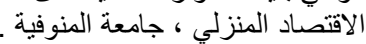

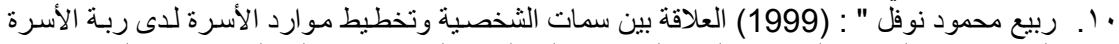

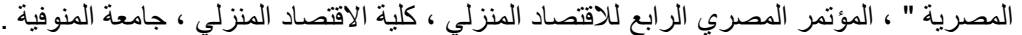

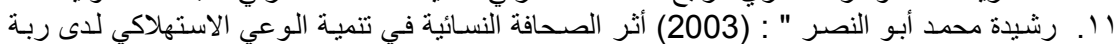

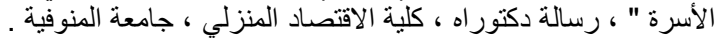

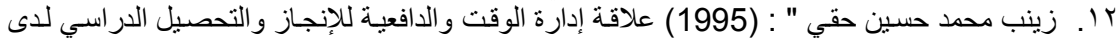

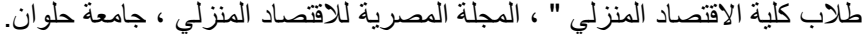

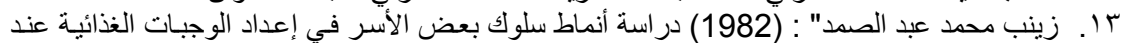

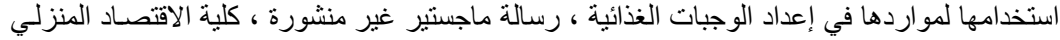

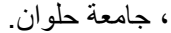

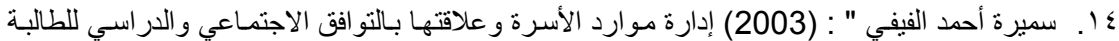

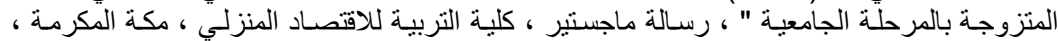
جامعة أم القرى .

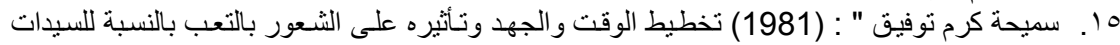

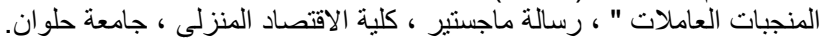

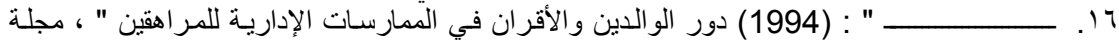
الاقتصاد المنزلي ، العدد العاثر.

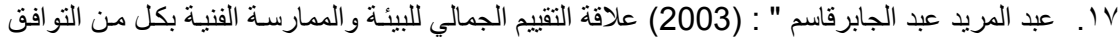

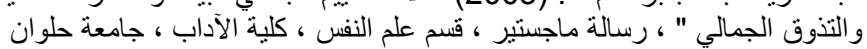

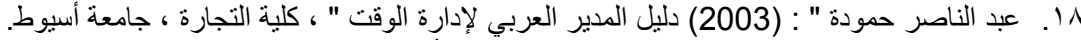

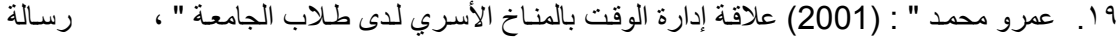

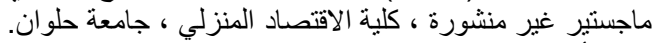

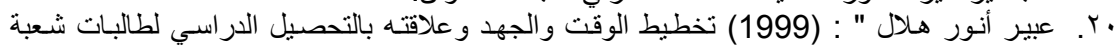

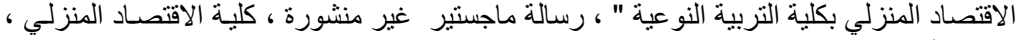
جامعة المنوفية . 


$$
\begin{aligned}
& \text { اY. فرج عبد القادر " : (1990) أصول علم النفس الحديث " ، دار المعارف ، القاهرة. }
\end{aligned}
$$

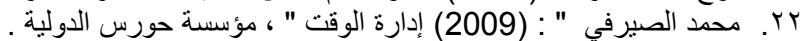

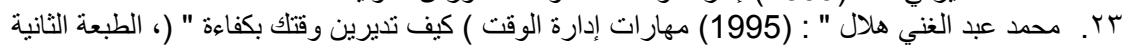

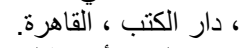

$$
\begin{aligned}
& \text { ؟r. مها سليمان أبو طالب " : (1991) أثر إدارة الدخل الأسري الغذائي على نمط الاستهلاك الغذائي }
\end{aligned}
$$

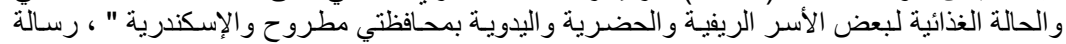

$$
\begin{aligned}
& \text { دكتور اه غير منشورة ، كلية الزر اعة الزية ، جامعة الإسكندرية. }
\end{aligned}
$$

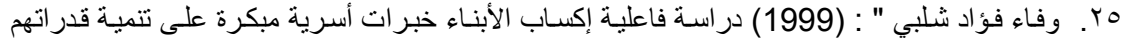

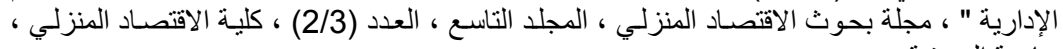

$$
\begin{aligned}
& \text { جامعة المنوفية. }
\end{aligned}
$$

26 .Dammer Beck, Anne M. (1995) : "The Political Economy of the Family a Study of Household Time Use Decision, University of Missouri, Colombia.

Glick, p. (1993) : "27.Time allocation decisions of urban woman in developing country . Ph.D. Thesis, The American University.

28. Hessing, M. (1994) : "More than clockwork: Woman's time management in their

29.Stewart , D.A; Stein,A.Forrest , G.C\&Clark , D.M(1992) : " Psycholosocial adjustment in siblings of Children with Chroniclife threatening illness ; aresearch note

\title{
PRACTICES OF FEMALE UNIVERSITY STUDENTS TOWARDS THE USE OF TIME RESOURCE And AWARENESS OF IT AND ITS RELATIONSHIP TO THE ASPECTS OF COMPATIBILITY WITH THEM \\ Rehan, E. R.; Heba D. A. Elassal and E. E. Ahmed \\ Faculty of Specific Education ., Mansoura University
}

\begin{abstract}
The current study aims to identify the nature of the relationship between the level of awareness and practice of undergraduate students towards the use of time resource and between aspects of personal, social and family compatibility with them, clarifying the relationship between the level of undergraduate students exercise of time resource and the awareness level of the value of this resource, study the differences between students in literary and scientific level towards the use of time resource, determining the relationship between social and economic characteristics of the student (such as Age - Marital Status - College - Study level (division) - The number of family members - expense - expense taken - residential environment - father level of education - father career - level of mother education - mother's profession) and the students level of awareness of time resource .

The study sample consisted of (200) students from Mansoura University including (99) students from scientific faculty represented by the Faculty of Science, (101) students from literary faculty represented by the College of Education.
\end{abstract}


Rehan, E. R. et al.

The study proved that there is a statistically significant relationship between the consciousness of undergraduate students towards the use of time resource and the aspects of compatibility with them, such that results proved the existence of indicating correlation between consciousness of time resource as whole, except for the evaluation stage, and between aspects of compatibility with the exception of social compatibility, and there are significant statistical relationship between practice undergraduate students towards the use of time resource and aspects of compatibility with them , where results proved the lack of significant correlation between the practice of female students for a time resource, except for planning and implementation phases, and between aspects of compatibility with the exception of personal, family compatibility, there is statistically significant relationship between the level of awareness of undergraduate students towards the use of time resource and the level of their practicing time resource, where results proved existence of statistically significant correlation between the undergraduate students consciousness of time resource at all levels and the level of engaging time resource at all levels, there is no statistically significant differences between the level of undergraduate students (scientific - literary ) awareness of the use of time resource, except the implementation phase, there is no statistically significant differences between the level of undergraduate students (scientific - literary ) exercising time resource, except the implementation phase, there is no statistically significant relationship between economic and social characteristics of the student and the awareness of time resource, where results proved the lack of statistically significant correlation between the economic and social characteristics of the student and awareness of time resource, except for the level of the father education in the planning stage, there is no statistically significant relationship between economic and social characteristics of the student and the practice of time resource .

One of the most important recommendations of the study is the need to provide courses and training programs for university students about how to manage their time in accordance with what best fits the needs of the family and keep pace with modern changes, the importance of introducing some home management approaches such as time resource management in various disciplines

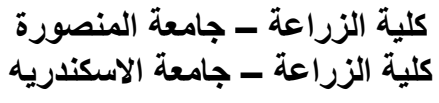

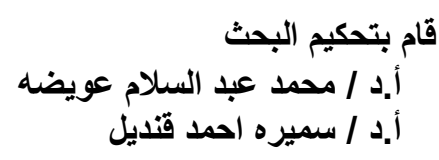


J. Agric. Econom. and Social Sci., Mansoura Univ., Vol.4 (6), June, 2013 

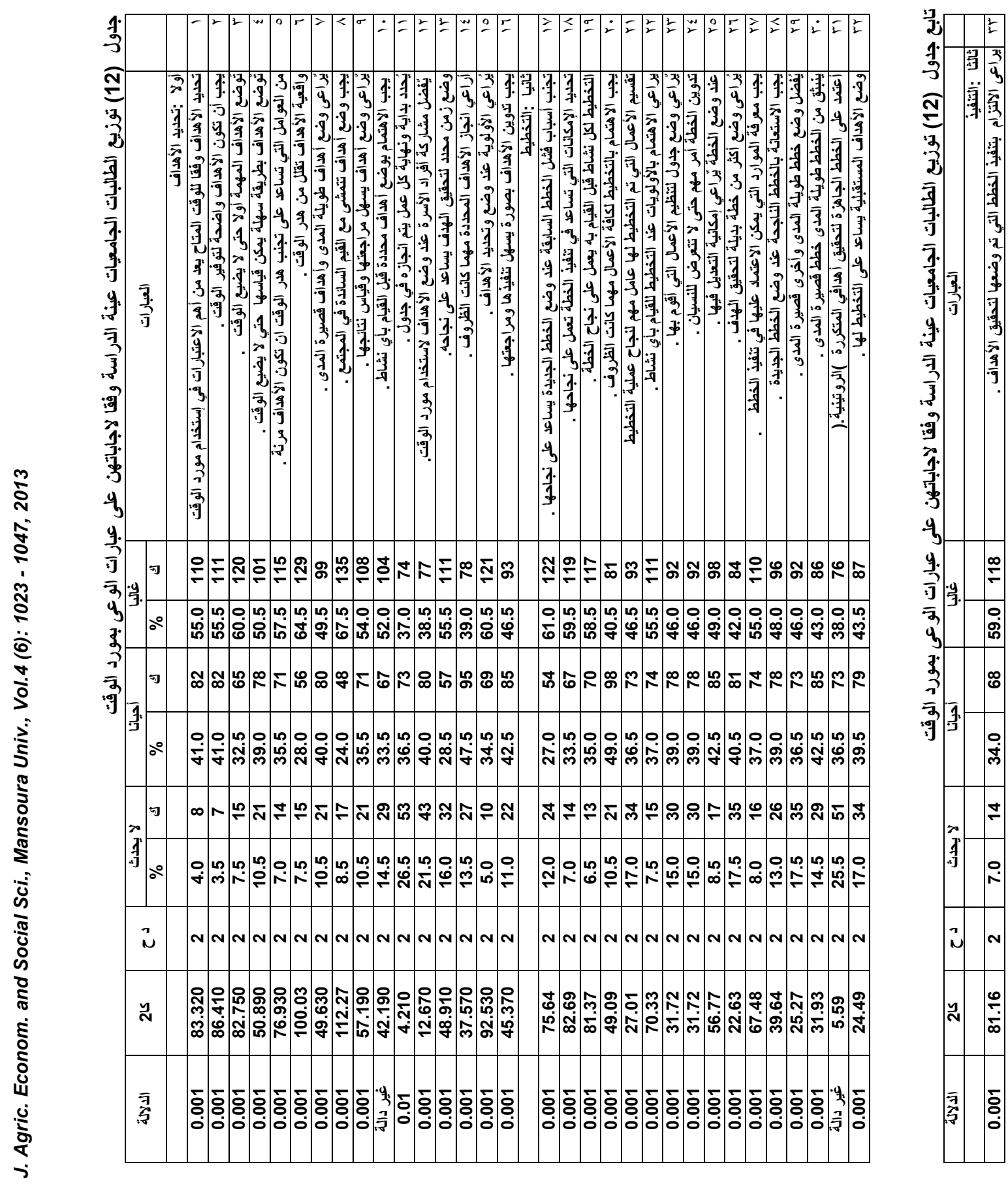


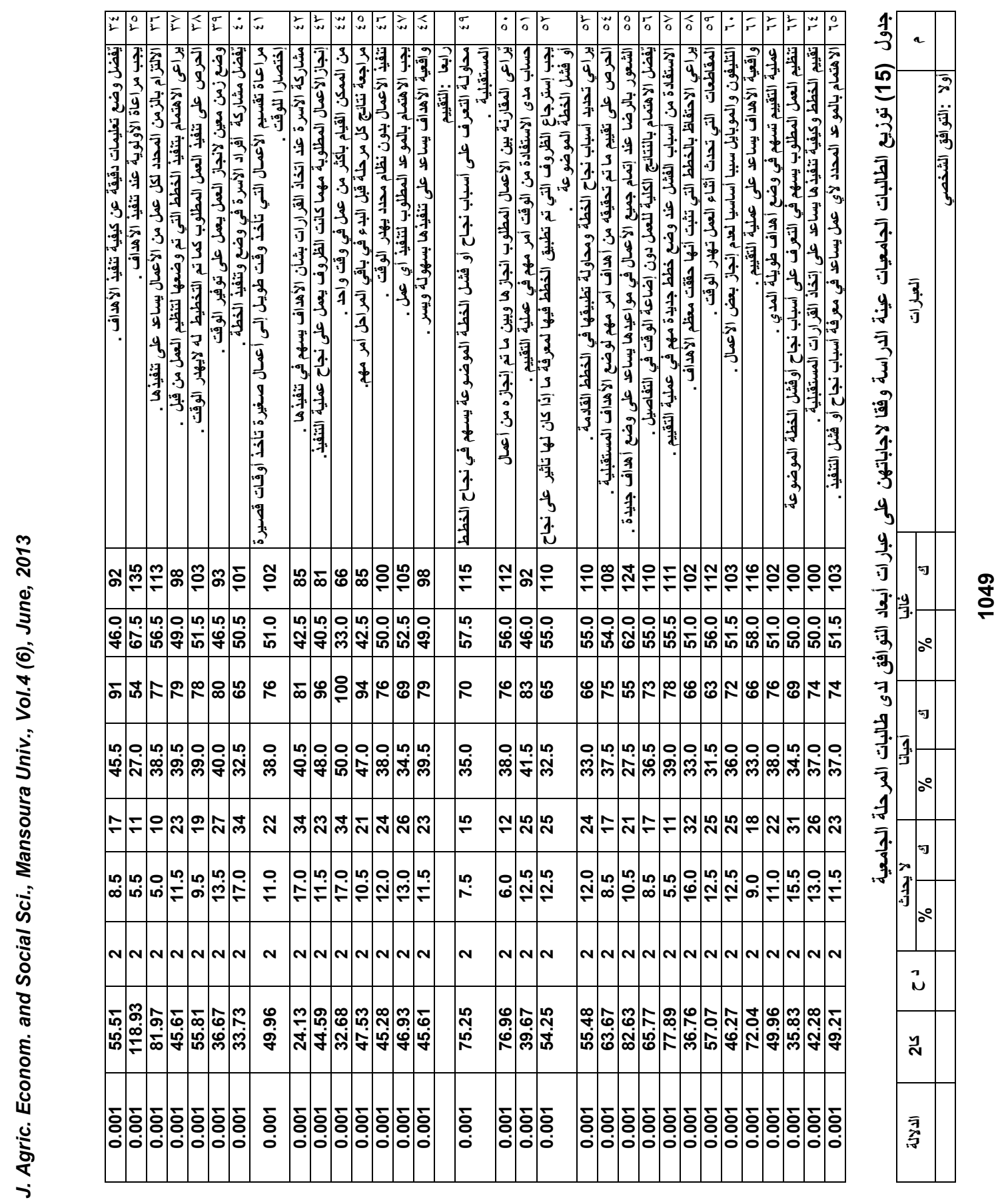




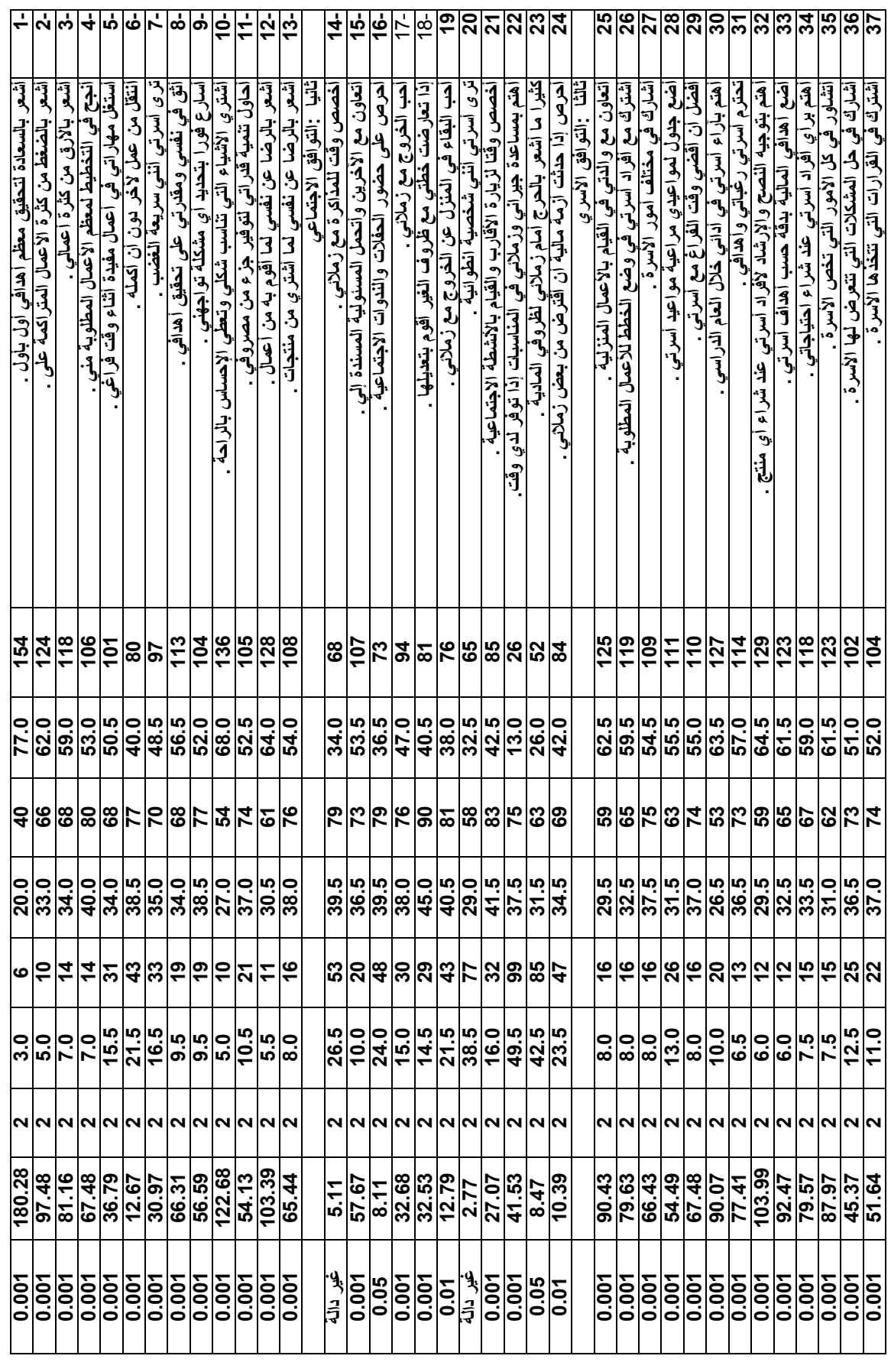

